\title{
Structure and biosynthesis of desmamides A-C, lipoglycopeptides from the endophytic cyanobacterium Desmonostoc muscorum LEGE 12446.
}

Sara Freitas, ${ }^{1,2}$ Raquel Castelo-Branco, ${ }^{1}$ Arlette Wenzel-Storjohann ${ }^{3}$, Vitor M. Vasconcelos ${ }^{1,2}$, Deniz Tasdemir ${ }^{3,4}$ and Pedro N. Leão, ${ }^{1, *}$

${ }^{1}$ Interdisciplinary Centre of Marine and Environmental Research (CIIMAR/CIMAR), University of Porto, Avenida General Norton de Matos, s/n 4450-208 Matosinhos (Portugal)

${ }^{2}$ Department of Biology, Faculty of Sciences, University of Porto Rua do Campo Alegre, 4169-007 Porto (Portugal)

${ }^{3}$ GEOMAR Centre for Marine Biotechnology (GEOMAR-Biotech), Research Unit Marine Natural Product Chemistry, GEOMAR Helmholtz Centre for Ocean Research Kiel, Am Kiel Kanal 44, 24106 Kiel, Germany

${ }^{4}$ Kiel University, Christian-Albrechts-Platz 4, 24118 Kiel, Germany

\section{Abstract}
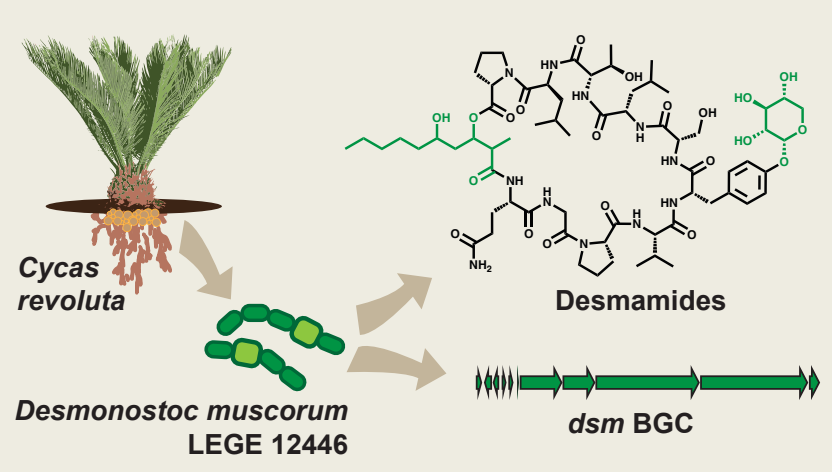

Certain cyanobacteria of the secondary metabolite-rich order Nostocales can establish permanent symbioses with a large number of cycads, by accumulating in their coralloid roots and shifting their metabolism to dinitrogen fixation. Here, we report the discovery of two novel lipoglycopeptides, desmamides A (1) and B (2), together with their aglycone desmamide C (3), from the nostocalean cyanobacterium Desmonostoc muscorum LEGE 12446 isolated from a cycad (Cycas revoluta) coralloid root. The chemical structures of the compounds were elucidated using a combination of 1D and 2D Nuclear Magnetic Resonance (NMR) spectroscopy and Mass Spectrometry (MS). The desmamides are decapeptides, featuring $\mathrm{O}$-glycosylation of tyrosine (in $\mathbf{1}$ and $\mathbf{2}$ ) and an unusual 3,5-dihydroxy-2-methyldecanoic acid residue. The biosynthesis of the desmamides was studied by substrate feeding experiments and bioinformatics. We describe herein the $d s m$ biosynthetic gene cluster (BGC) and propose it to be associated with desmamide production. The discovery of this class of very abundant (>1.5\% d.w.) bacterial lipoglycopeptides paves the way for exploration of their potential role in root endosymbiosis. 


\section{Introduction}

Cyanobacteria are photoautotrophic bacteria found in a wide range of environments and exist in single-celled, colonial, filamentous and branched filamentous forms. ${ }^{1}$ These organisms can also differentiate specialized cells, ${ }^{1}$ such as heterocysts, which carry out nitrogen fixation ${ }^{2}$ and are the hallmark of the Nostocales, a latebranching order within the Cyanobacteria phylum. Nostocalean cyanobacteria typically have large genomes, complex morphological features and can either be free-living, obligate symbionts of the water fern Azolla or facultative symbionts of other organisms, such as cycads, mosses, liverworts, and fungi. ${ }^{1,3}$ In cycads, the cyanobacterial holobiont forms a conspicuous circular layer in the coralloid roots. ${ }^{4}$ Free-living cyanobacterial holobionts are recruited by the plant and can invade their host at different stages of root development. ${ }^{3,4}$ Once inside the roots, the cyanobacteria increase their heterocyst differentiation frequency to fix nitrogen for the host, and establish a permanent symbiosis under complete darkness. ${ }^{3,4}$ Cyanobacteria within the order Nostocales present relatively large genomes (average $7.6 \mathrm{~Gb})^{5}$ which typically contain between 10 and 30 biosynthetic gene clusters (BGCs), encoding the production of several classes of natural products. ${ }^{6}$ These include terpenes, alkaloids, peptides of ribosomal (RiPPs) or non-ribosomal (NRPs) origin, polyketides and hybrids thereof. ${ }^{6,7}$ The chemical talent of members of the Nostocales was well-recognized before the genomic era: early discoveries of natural products from this order include remarkable structures such as the cylindrocyclophanes, ${ }^{8}$ hapalindoles and related alkaloids, ${ }^{9}$ cryptophycins ${ }^{10}$ and scytonemin. ${ }^{11}$ Symbiotic Nostocales are known to be rich producers of secondary metabolites, ${ }^{12,13}$ some of which have been shown to mediate interactions with the host. ${ }^{14,15}$ For example, the facultative cycad symbiont cyanobacterium Nostoc punctiforme PCC 73102 produces the nostopeptolides, cyclic lipopeptides whose production is regulated by the plant host and are involved in crosstalk between the two organisms. ${ }^{15}$ A large variety of cyanobacteria and, in particular, members of the order Nostocales, produce cyclic lipopeptides. ${ }^{16}$ These compounds are usually synthesized by hybrid polyketide synthase/non-ribosomal peptide synthetase (PKS/NRPS) pathways, which yields a fatty acyl moiety (that can be modified to varying degrees) connected to a peptidic component. ${ }^{16}$ Cyanobacterial cyclic lipopeptides are structurally diverse and typically exhibit antifungal activity; however their precise ecological roles are mostly unknown. ${ }^{16}$

A very small fraction of natural cyclic lipopeptides - from cyanobacteria or other organisms - are glycosylated and referred to as lipoglycopeptides. This designation has been used to encompass both glycosylated lipopeptides and acylated glycopeptides. ${ }^{17,18}$ Natural lipoglycopeptides are rare and are grouped in a small number of structural classes: the cyanobacterial hassallidins/balticidins, ${ }^{19,20}$ the actinobacterial teicoplanin/teichomycins, ${ }^{21}$ mannopeptimycins $(\gamma, \delta$ and $\varepsilon),{ }^{22}$ ramoplanins ${ }^{23}$ and gausemycins, ${ }^{18}$ as well as occidiofungins produced by a Gram-negative Burkholderia strain. ${ }^{24}$ Potent antibacterial or antifungal activities are associated with each of these compound classes; teicoplanin and related semisynthetic lipoglycopeptides are used in the clinic to treat serious infections caused by Gram-positive bacteria. ${ }^{25}$

In this study, we report the chemical exploration of the nostocalean cyanobacterium Desmonostoc muscorum LEGE 12446, a plant facultative symbiont isolated from a cycad (Cycas revoluta) coralloid root. Metabolomic analysis of a pre-fractionated organic extract of this cyanobacterium led to the detection and eventual isolation of two abundant metabolites, desmamides A (1) and B (2), which represent a new structural class of lipoglycopeptides. Their aglycone - desmamide C (3) - was also isolated in this effort. The biosynthesis of 1-3 was investigated and a putative biosynthetic gene cluster (BGC) associated with desmamide production - $d s m$ - was identified. Compounds $\mathbf{1}$ and $\mathbf{2}$ showed moderate cytotoxic activity towards cancer cell lines, and inhibited the growth of the plant pathogenic bacterium Xanthomonas campestris with moderate potency.

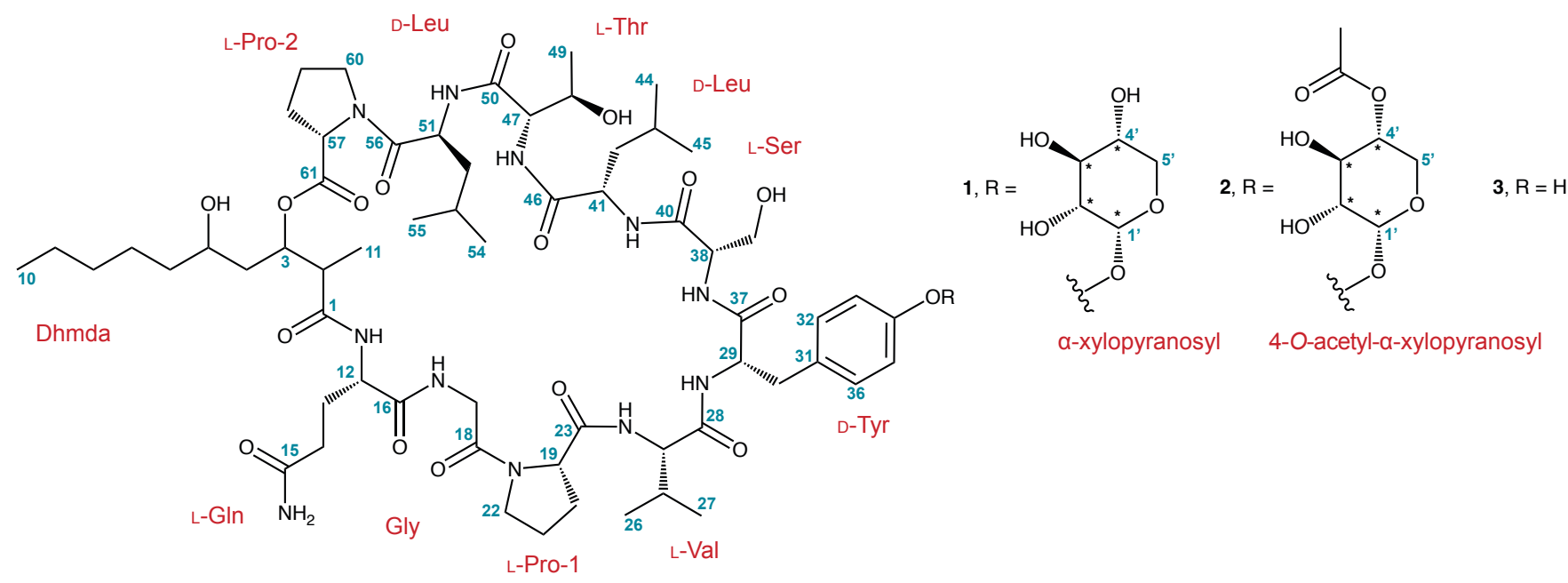

Figure 1. Structures of desmamides A-C (1-3). 


\section{Results and Discussion}

MS-guided isolation of desmamides A-C (1-3). As part of our ongoing investigations of the chemical diversity of cyanobacteria from the LEGE culture collection (LEGEcc) ${ }^{26}$ we carried out an exploration of a xenic, unicyanobacterial culture of D. muscorum LEGE 12446. The biomass from a small-scale laboratory culture of $D$. muscorum was extracted with $\mathrm{CH}_{2} \mathrm{Cl}_{2} / \mathrm{MeOH}(2: 1$, $\mathrm{v} / \mathrm{v}$ ) and fractionated in a SPE column. Global Natural Products Social Molecular Networking (GNPS) ${ }^{27}$ analysis of the resulting fractions revealed the presence of a cluster comprised of five mass features in the fraction eluting with $100 \% \mathrm{MeOH}$, two of which had close retention time values and $[\mathrm{M}+\mathrm{H}]^{+}$ions with $\mathrm{m} / z$ 1388.750, and 1256.714 (Fig. S1; Table S1). Dereplication using GNPS tools Dereplicator, ${ }^{28}$ Dereplicator VarQuest ${ }^{29}$ and Dereplicator ${ }^{30}$ as well as manual searches on the Dictionary of Natural Products database $^{31}$ and Natural Products Atlas ${ }^{32}$ returned no hits, confirming the novelty of the compounds. To obtain sufficient amounts of the natural products for NMR-based structure elucidation and biological activity testing, the strain was grown in large-scale $(160 \mathrm{~L})$, which yielded $70.3 \mathrm{~g}$ of dry biomass. Repeated percolation with $\mathrm{CH}_{2} \mathrm{Cl}_{2} / \mathrm{MeOH}(2: 1, \mathrm{v} / \mathrm{v})$ afforded an organic extract (14.7 g) that contained the target mass features, as revealed by Liquid Chromatography coupled to High Resolution Electrospray Ionization Mass Spectrometry (LC-HRESIMS) analysis, enabling a MS-guided isolation approach (Fig. S2). To this end, we performed a normalphase Vacuum Liquid Chromatography (VLC) of the organic extract to obtain 13 fractions of increasing polarity. LC-HRESIMS analysis indicated that the compounds were abundant in fractions eluting with 1:2 and 3:7 EtOAc: $\mathrm{MeOH}(\mathrm{v} / \mathrm{v})$. These fractions were combined $(2.90 \mathrm{~g})$ and LC-HRESIMS analysis was used to follow the targeted mass features over a series of chromatographic procedures. Normal phase flash chromatography, reversed-phase chromatography on a pre-packed SPE cartridge, semi-preparative and analytical HPLC were necessary to obtain pure desmamides A (1, $26.3 \mathrm{mg})$ and $\mathrm{B}(\mathbf{2}, 20.4 \mathrm{mg})$, together with their aglycone, desmamide $\mathrm{C}(\mathbf{3}, 4.0 \mathrm{mg})$. Compounds $\mathbf{1}$ and $\mathbf{3}$ correspond to the two GNPS-detected mass features targeted, while compound 2 was obtained during isolation of $\mathbf{1}$. A considerable amount of 1-3 remained in adjacent chromatography fractions - we estimate, based on LCHRESIMS quantification (Fig. S3, Table S2), that the combined mass of these metabolites reaches $235 \mathrm{mg}$ in the initial extract (1.6\% of dry cell material).

A

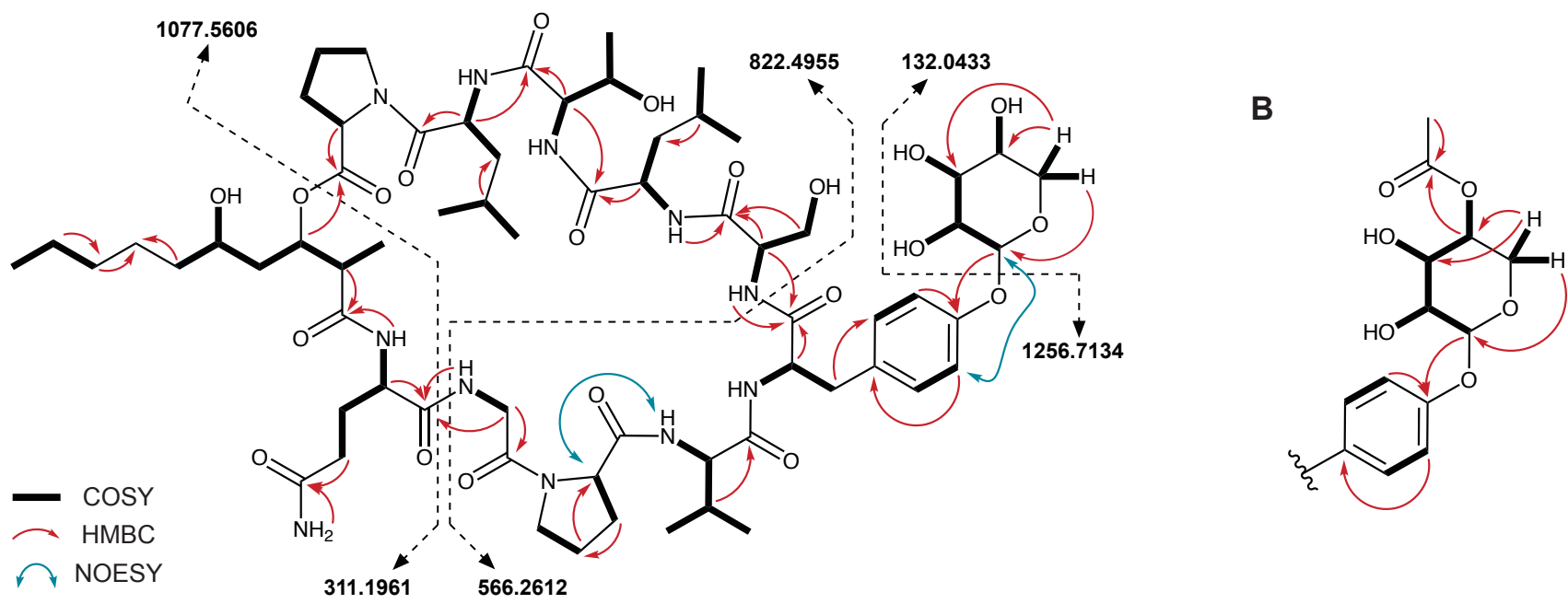

C

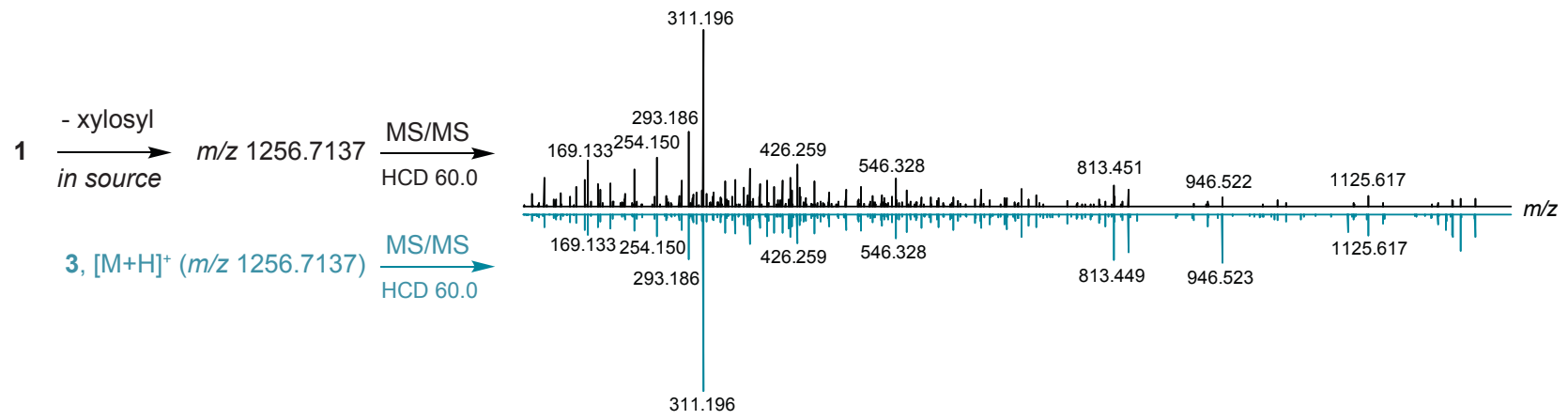

Figure 2. Structure elucidation of 1-3. A - Key HMBC, COSY and NOESY correlations and HRMS/MS fragmentations supporting the structure proposal for 1. B - Key HMBC and COSY correlations supporting the presence of a 4-O-acetylxylopyranosyl-Tyr moiety. C - Comparison of the HRESIMS/MS spectra of the aglycone of $\mathbf{1}$ (isolated in-source) and of compound $\mathbf{3}$, supporting that they are identical. 
Table $1-{ }^{1} \mathrm{H}(400 \mathrm{MHz})$ and ${ }^{13} \mathrm{C}(100 \mathrm{MHz})$ NMR Spectroscopic Data for desmamide A (1) in DMSO-d 6 .

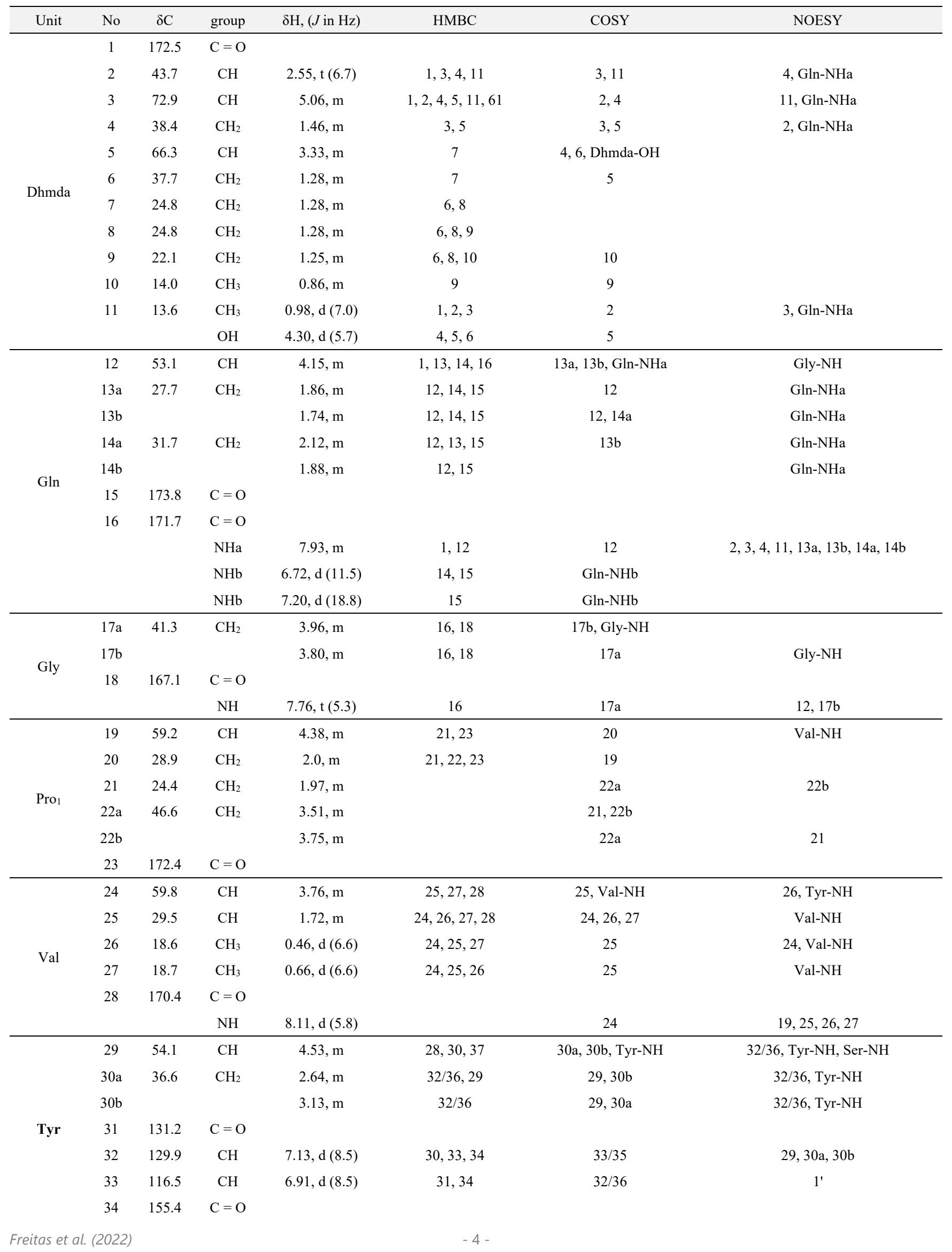




\begin{tabular}{|c|c|c|c|c|c|c|c|}
\hline & 35 & 116.5 & $\mathrm{CH}$ & $6.91, \mathrm{~d}(8.5)$ & $30,33,34$ & $32 / 36$ & $1^{\prime}$ \\
\hline & 36 & 129.9 & $\mathrm{CH}$ & $7.13, \mathrm{~d}(8.5)$ & 31,34 & $33 / 35$ & $29,30 \mathrm{a}, 30 \mathrm{~b}$ \\
\hline & 37 & 171.5 & $\mathrm{C}=\mathrm{O}$ & & & & \\
\hline & & & $\mathrm{NH}$ & $8.21, \mathrm{~d}(8.4)$ & 28 & 29 & $24,29,30 a, 30 b$ \\
\hline \multirow{6}{*}{ Ser } & 38 & 56.5 & $\mathrm{CH}$ & $4.16, \mathrm{~m}$ & $37,39,40$ & Ser-NH & $39 a$ \\
\hline & $39 a$ & 61.5 & $\mathrm{CH}_{2}$ & $3.65, \mathrm{~m}$ & 40 & Ser-OH & 38, Ser-NH \\
\hline & $39 b$ & & & $3.75, \mathrm{~m}$ & 40 & Ser-OH & \\
\hline & 40 & 169.8 & $\mathrm{C}=\mathrm{O}$ & & & & \\
\hline & & & $\mathrm{NH}$ & $8.08, \mathrm{~d}(6.8)$ & $37,38,39$ & 38 & 29, 39a, Ser-OH, Leu $1-\mathrm{NH}$ \\
\hline & & & $\mathrm{OH}$ & $5.13, \mathrm{t}(6.1)$ & 39 & $39 a, 39 b$ & Ser-NH \\
\hline \multirow{7}{*}{ Leu $_{1}$} & 41 & 48.8 & $\mathrm{CH}$ & $4.32, \mathrm{~m}$ & & $\mathrm{Leu}_{1}-\mathrm{NH}$ & $42, \mathrm{Leu}_{1}-\mathrm{NH}$ \\
\hline & 42 & 40.3 & $\mathrm{CH}_{2}$ & $1.42-1.50, \mathrm{~m}$ & $41,43,44 / 45$ & & 41, Leu $1-\mathrm{NH}$ \\
\hline & 43 & 24.0 & $\mathrm{CH}$ & $1.64, \mathrm{~m}$ & $42,44 / 45$ & $44 / 45$ & \\
\hline & 44 & 23.2 & $\mathrm{CH}_{3}$ & $0.87, \mathrm{~m}$ & 43 & 43 & \\
\hline & 45 & 23.2 & $\mathrm{CH}_{3}$ & $0.87, \mathrm{~m}$ & 43 & 43 & \\
\hline & 46 & 172.1 & $\mathrm{C}=\mathrm{O}$ & & & & \\
\hline & & & $\mathrm{NH}$ & $7.55, \mathrm{~d}(8.0)$ & 40 & 41 & 41, 42, Ser-NH, Thr-NH \\
\hline \multirow{6}{*}{ Thr } & 47 & 58.3 & $\mathrm{CH}$ & $4.19, \mathrm{~m}$ & $46,48,49,50$ & Thr-NH & 48,49 \\
\hline & 48 & 66.8 & $\mathrm{CH}$ & $3.91, \mathrm{~m}$ & 50 & $49, \mathrm{Thr}-\mathrm{OH}$ & 47, Thr-NH, Leu $2-\mathrm{NH}$ \\
\hline & 49 & 19.4 & $\mathrm{CH}_{3}$ & $1.0, \mathrm{~d}(6.4)$ & 47,48 & 48 & 47, Thr-OH \\
\hline & 50 & 169.5 & $\mathrm{C}=\mathrm{O}$ & & & & \\
\hline & & & $\mathrm{NH}$ & $7.87, \mathrm{~d}(7.5)$ & $46,47,48$ & 47 & 48, $\mathrm{Leu}_{1}-\mathrm{NH}, \mathrm{Thr}-\mathrm{OH}$ \\
\hline & & & $\mathrm{OH}$ & $4.90, \mathrm{~d}(4.6)$ & $47,48,49$ & 48 & 49, Thr-NH \\
\hline \multirow{7}{*}{$\mathrm{Leu}_{2}$} & 51 & 48.8 & $\mathrm{CH}$ & $4.65, \mathrm{~m}$ & 50,56 & $52, \mathrm{Leu}_{2}-\mathrm{NH}$ & \\
\hline & 52 & 41.1 & $\mathrm{CH}_{2}$ & $1.48, \mathrm{~m}$ & $51,53,54 / 55$ & 51 & $\mathrm{Leu}_{2}-\mathrm{NH}$ \\
\hline & 53 & 24.0 & $\mathrm{CH}$ & $1.64, \mathrm{~m}$ & $52,54 / 55$ & $54 / 55$ & \\
\hline & 54 & 21.4 & $\mathrm{CH}_{3}$ & $0.83, \mathrm{~m}$ & 52,53 & 53 & \\
\hline & 55 & 21.4 & $\mathrm{CH}_{3}$ & $0.83, \mathrm{~m}$ & 52,53 & 53 & \\
\hline & 56 & 170.6 & $\mathrm{C}=\mathrm{O}$ & & & & \\
\hline & & & $\mathrm{NH}$ & $7.57, \mathrm{~d}(8.0)$ & 50 & 51 & 48,52 \\
\hline \multirow{5}{*}{$\mathrm{PrO}_{2}$} & 57 & 59.0 & $\mathrm{CH}$ & $4.27, \mathrm{~m}$ & $58,59,61$ & 58 & $59,3^{\prime}$ \\
\hline & 58 & 28.5 & $\mathrm{CH}_{2}$ & $2.13, \mathrm{~m}$ & & 57,59 & \\
\hline & 59 & 24.7 & $\mathrm{CH}_{2}$ & $1.85, \mathrm{~m}$ & 58,60 & 58,60 & 57 \\
\hline & 60 & 45.9 & $\mathrm{CH}_{2}$ & $3.46, \mathrm{~m}$ & & 59 & \\
\hline & 61 & 171.4 & $\mathrm{C}=\mathrm{O}$ & & & & \\
\hline \multirow{9}{*}{ Xylosyl } & $1^{\prime}$ & 97.6 & $\mathrm{CH}$ & $5.31, \mathrm{~d}(3.5)$ & $34,63,64,66$ & $2^{\prime}$ & $33 / 35$ \\
\hline & $2^{\prime}$ & 71.6 & $\mathrm{CH}$ & $3.36, \mathrm{~m}$ & 64,66 & 1', OHa & \\
\hline & $3^{\prime}$ & 73.2 & $\mathrm{CH}$ & $3.55, \mathrm{~m}$ & 63,65 & $\mathrm{OHb}$ & 57 \\
\hline & $4^{\prime}$ & 69.7 & $\mathrm{CH}$ & $3.34, \mathrm{~m}$ & 64,66 & & \\
\hline & $5 ' \mathrm{a}$ & 62.5 & $\mathrm{CH}_{2}$ & $3.45, \mathrm{~m}$ & $62,64,65$ & $5^{\prime} \mathrm{b}$ & \\
\hline & $5^{\prime} \mathrm{b}$ & & & $3.33, \mathrm{~m}$ & 62 & $5^{\prime} \mathrm{a}$ & $\mathrm{OHb}, \mathrm{OHc}$ \\
\hline & & & $\mathrm{OHa}$ & $5.01, \mathrm{~d}(6.2)$ & - & $2^{\prime}$ & \\
\hline & & & $\mathrm{OHb}$ & $4.93, \mathrm{~d}(4.9)$ & $63,64,65$ & $3^{\prime}$ & $5 ' b$ \\
\hline & & & $\mathrm{OHc}$ & $4.99, \mathrm{~d}(4.8)$ & 65,66 & & $5^{\prime} \mathrm{b}$ \\
\hline
\end{tabular}

${ }^{a}$ from HSQC, ${ }^{b}$ from proton to indicated carbon. 
Structure elucidation of 1-3. We focused our structure elucidation efforts on the most abundant metabolite - 1. High Resolution Electrospray Ionization Mass Spectrometry (HRESIMS) analysis of 1 showed a $m / z 1388.7577$ for the $[\mathrm{M}+\mathrm{H}]^{+}$ion (Fig. S4). This was consistent with a molecular formula of $\mathrm{C}_{66} \mathrm{H}_{105} \mathrm{~N}_{11} \mathrm{O}_{21}$ (calcd 1388.7565, $\left.[\mathrm{M}+\mathrm{H}]^{+}\right)$and the presence of 20 degrees of unsaturation. Inspection of the ${ }^{1} \mathrm{H}$ and ${ }^{13} \mathrm{C}$ APT NMR data $(400 \mathrm{MHz}$, DMSO- $d_{6}$ ) of 1 (Table 1, Figs. S5-S6) quickly revealed the presence of the anomeric proton $\left(\mathrm{H}-1^{\prime}, \delta_{\mathrm{C}} 97.6, \delta_{\mathrm{H}} 5.31 J_{1^{\prime}-2^{\prime}} 3.5 \mathrm{~Hz}\right)$ of a sugar unit. Multiple resonances consistent with the exchangeable $\mathrm{NH}$ protons $\left(\delta_{\mathrm{H}} 8.5-7.50\right)$, amide carbons $\left(\delta_{\mathrm{C}} 175-165\right)$ and alpha positions of amino acid residues $\left(\delta_{\mathrm{C}} 60-40, \delta_{\mathrm{H}} 4.5-3.5\right)$ were observed (Table 1). Furthermore, an aliphatic terminal methyl group triplet $\left(\mathrm{CH}_{3}-10, \delta_{\mathrm{C}} 14.0, \delta_{\mathrm{H}} 0.86\right)$ and a small methylene envelope $\left(\delta_{\mathrm{H}} 1.28-1.25\right)$ were clearly identified (Table 1$)$. These observations collectively suggested that $\mathbf{1}$ was a lipoglycopeptide. Combined analysis of 1D and 2D (HSQC, HMBC and COSY) NMR data for 1 (Table 1, Figs. 2, S5-S11) indicated that a major conformer and at least one minor conformer existed in solution, complicating the interpretation of the NMR spectra. Still, our analysis enabled the assembly of several structural fragments (Fig. 2A), including those of a number of proteinogenic amino acid residues (Thr, Ser, Gln, two Pro, Val, Gly and two Leu). Furthermore, it was possible to establish the presence of a Tyr residue featuring $O$-glycosylation with an aldopentose pyranose ring, as the anomeric proton showed an HMBC correlation to C-34 and NOE correlation to $\mathrm{H}-33 / 35$. Determination of the nature of the sugar residue connected to Tyr in $\mathbf{1}$ was hampered by extensive overlap of the sugar proton multiplet signals, limiting our ability to measure the associated coupling constants. Still, the clear $J_{1^{\prime}-2^{\prime}}$ value of $3.5 \mathrm{~Hz}$ for the anomeric proton $\left(\mathrm{H}-1^{\prime}\right)$ indicated $\alpha$-glycosylation. To identify the chemical nature of the sugar unit in $\mathbf{1}$, we carried out an acid hydrolysis to free the sugar unit, followed by HPLC analysis of 1phenyl-3-methyl-5-pyrazolone (PMP)-derivatives of ribose, xylose and arabinose and of the hydrolysed sugar residue of $\mathbf{1}$. Interestingly, this analysis indicated that xylose was the most abundant sugar in $\mathbf{1}(\sim 80 \%)$, but arabinose was also found to a smaller extent $(\sim 20 \%$, from LC-HRESIMS, Fig. S12). Hence, it is possible that some of the predicted minor conformer resonances observed in the NMR data for 1 could actually correspond to this arabinose-bearing, co-eluting minor compound. The presence of an $\alpha$-methylated and $\beta$ - and $\delta$-hydroxylated acyl moiety could also be deduced from the NMR data. This spin system was supported by HMBC and COSY correlations (Fig. 2A) and degenerated into aliphatic methylenes, which could be connected by HMBC correlations to a terminal linear alkane moiety (Fig. 2A). Hence, this residue was found to correspond to 3,5-dihydroxy-2-methyldecanoic acid (Dhmda) residue, $O$-substituted at C-3 (Fig. 2A). Due to poor resolution of the multiple amide carbon resonances, inter-residue connectivity could not be unambiguously established from the initial HMBC data acquired for $\mathbf{1}$. To circumvent this, we resorted to a band-selective constant-time $\mathrm{HMBC}^{33}$ experiment (Fig. S11). The increased resolution in the amide $\delta_{\mathrm{C}}$ resonance region and enabled the determination of the connectivity between the NMR-derived residues for $\mathbf{1}$, with the exception of the (Pro-1)-Val connectivity (Fig. 2A). Nevertheless, a cyclic peptide would be required to satisfy the degrees of unsaturation, and the connectivity between Pro and Val was supported by NOE data (Fig. 2A). From HRESIMS/MS analysis of 1, the residue sequences [Dhmda-GlnGly-Pro-Val-Tyr] and [Tyr-Ser-Leu-Thr-Leu-Pro-Dhmda-Gln] could be established (Fig. 2A, Fig. S13-14), which validated the NMR-derived findings.

The 1D and 2D NMR data of 2 in DMSO- $d_{6}$ (Table S3, Figs. S15S19) was found to be highly similar to those of 1 . In HRESIMS analysis, 2 showed a $\mathrm{m} / \mathrm{z} 1430.7666$ corresponding to a molecular formula $\mathrm{C}_{68} \mathrm{H}_{108} \mathrm{~N}_{11} \mathrm{O}_{22}\left(\right.$ calcd $m / z$ 1430.7665, $\left.[\mathrm{M}+\mathrm{H}]^{+}\right)$and 21 degrees of unsaturation (Fig. S20). The 42.0089 amu mass difference to $\mathbf{1}$ is consistent with the presence of an acetyl substitution $\left(\mathrm{C}_{2} \mathrm{H}_{2} \mathrm{O}\right.$, calcd $\left.42.0106 \mathrm{amu}\right)$. Comparison of the ${ }^{1} \mathrm{H}$ and ${ }^{13} \mathrm{C}$ NMR data of $\mathbf{1}$ and $\mathbf{2}$ revealed the differences to be associated with the sugar resonances, including those of C-3'/4'/5' (Table S3). Also, a prominent sharp singlet $\left(\delta_{\mathrm{H}} 2.02, \mathrm{~s}, 3 \mathrm{H}\right)$ and an additional carbonyl resonance $\left(\delta_{\mathrm{C}} 170.0\right)$ were observed in 2. Analysis of $2 \mathrm{D}$ NMR data of this compound (Table S3, Figs. S15-S19) clarified that the latter signals corresponded to the suspected acetyl group, in particular through the ${ }^{2} J \mathrm{HMBC}$ correlation between the acetyl methyl to the carbonyl (Fig. 2B). An HMBC correlation between H-4' and this same carbonyl confirmed the acetylation of the $\mathrm{OH}$ group at $\mathrm{C}-4$ ' position of the sugar moiety (Fig. 2B). The acetylated sugar residue is proposed to be $\alpha$-xylopyranosyl, as in $\mathbf{1}$, on the basis of the small $J_{1}{ }^{\prime}-2$, value of $3.5 \mathrm{~Hz}\left(\mathrm{H}-1^{\prime}, \delta_{\mathrm{H}} 5.40\right)$, and from coupling constant analysis of ${ }^{1} \mathrm{H}$ and COSY data (Table S3, Fig. S20).

Compound 3 showed ${ }^{1} \mathrm{H}$ and ${ }^{13} \mathrm{C}$ NMR data in DMSO- $d_{6}$ (Fig. S21S22) similar to those of $\mathbf{1}$ and $\mathbf{2}$ but lacking the sugar signals, while featuring a broad singlet resonating at $\delta_{\mathrm{H}} 9.13$, characteristic of a phenol group exchangeable proton. As suggested by the NMR data, this metabolite was confirmed to be the aglycone of $\mathbf{1}$ and $\mathbf{2}$ on the basis of identical HRESIMS/MS spectra for $\mathbf{3}$ and for the in-source isolated aglycone ions of $\mathbf{1}$ and $\mathbf{2}$ (Fig. 2C, Fig. S23).

The absolute configuration of the chiral amino acid residues in $\mathbf{1}$ (and therefore, also in $\mathbf{2}$ and $\mathbf{3}$ ) was determined using chiral HPLC and Marfey's analysis. The Tyr residue and the two Leu residues were found to have D-configuration, while the remaining chiral amino acids were of L-configuration (Fig. S24-S25). We were unable to determine the absolute configuration of the $\alpha$-xylopyranosyl residue and thus report only relative configuration. Nevertheless, given the fact that L-xylose is very rare in nature, ${ }^{34}$ we propose a Dconfiguration for this sugar residue.

Compounds $\mathbf{1}$ and $\mathbf{2}$ are cyclic decapeptides that feature Tyr $O$-glycosylation and contain a modified fatty acyl residue as part of the macrocycle. This residue is connected through an amide bond to the $\mathrm{N}$-terminal amino acid and through an ester bond to the $\mathrm{C}$-terminus of the peptide chain. Desmamides A and B thus represent a novel lipoglycopeptide class, the second to be described in cyanobacteria after the hassallidins/balticidins. ${ }^{19,20}$ Unlike $\mathbf{1}$ and 2, these compounds are nonapeptides with an exocyclic fatty acyl residue connected to the N-terminal amino acid, which is also exocyclic. Several $O$-glycosylation patterns have been described for hassallidins/balticidins, occuring on the 3-hydroxy group of the fatty acyl moiety and/or on an endocyclic Thr residue. Compounds $\mathbf{1}$ and $\mathbf{2}$ are also structurally distinct from the other previously reported 
natural lipoglycopeptide scaffolds (Fig. S26). Nevertheless and remarkably, $O$-glycosylation of Tyr is observed in several of these, namely in mannopeptimycins $\gamma / \delta / \varepsilon^{22}$ and in the gausemycins. ${ }^{18}$ This decoration is also present in the fungal glycopeptide cycloaspeptide $\mathrm{F}^{35}$ and in cacaoidin, ${ }^{36}$ a recently described ribosomallysynthesized and post-translationally modified (RiPP) glycopeptide.
In the case of ramoplanin, $O$-glycosylation occurs in the non-proteinogenic amino acid Hpg (4-hydroxyphenylglycine), ${ }^{23}$ which is structurally similar to Tyr. Protection of the 4-OH position in sugar residues, as observed for $\mathbf{2}$, is also a feature of mannopeptimycins $\gamma / \delta / \varepsilon,{ }^{22}$ while several hassallidins contain acetylated sugar moieties. ${ }^{20}$ We could not find other examples of lipopeptides bearing a Dhmda moiety, nor shorter- or longer-chain versions thereof.

\section{A}

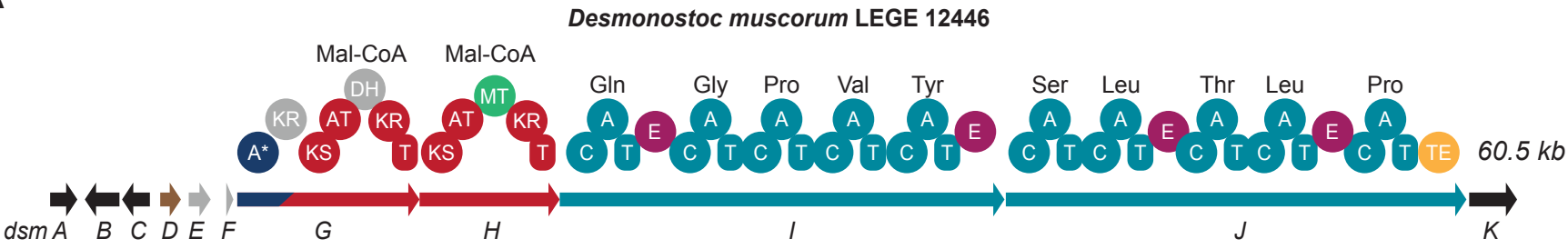

proposed functions:

transport

acyltransferase

fatty acyl-AMP

polyketide synthase

non-ribosomal peptide ligase (FAAL) (PKS)

B

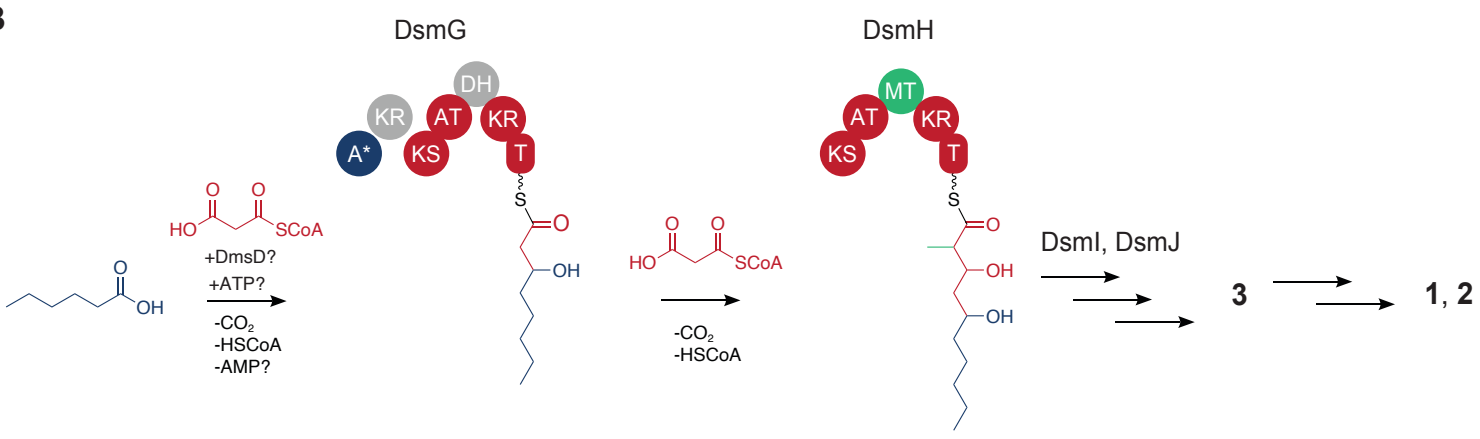

C

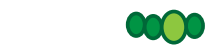

D. muscorum LEGE $12446+d_{11}$-hexanoic $/ d_{15}$-octanoic $/ d_{19}$-decanoic acid $\longrightarrow \begin{aligned} & \text { LC-HRESIMS } \\ & \text { (MeOH extract })\end{aligned}$

EICs

$\left([\mathrm{M}+\mathrm{Na}]^{+}, \pm 5 \mathrm{ppm}\right)$ :

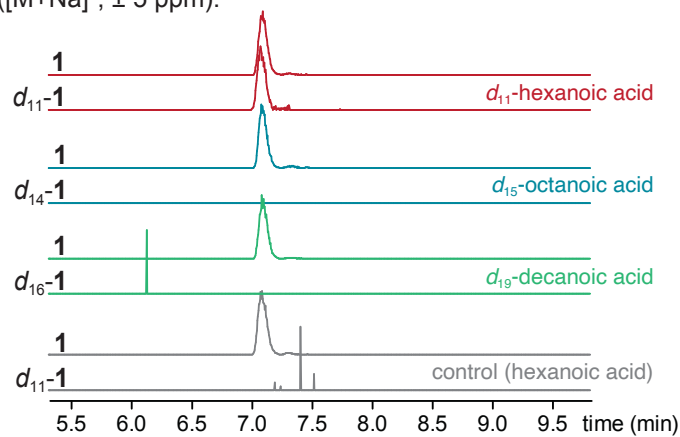

Full MS:

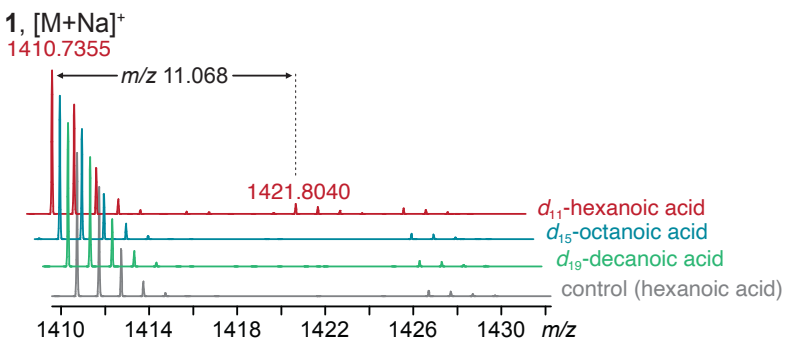

Figure 3. Biosynthesis of the desmamides A-C (1-3). A - Schematic representation of the dsm BGC, including the proposed functions of the predicted open-reading frames, domain composition of detected PKS and NRPS (or NRPS-like) modules, and bioinformatically-predicted (antiSMASH) monomers activated by acyl-tranferase (AT) or adenylation (A) domains. $A^{*}$ indicates an adenylation domain within a region with homology to a fatty acyl-AMP ligase (FAAL), proposed to activate hexanoic acid. B - Proposed biosynthetic steps leading to 1-3, highlighting the formation of the Dhmda residue from hexanoic acid, by PKS machinery. C - LC-HRESIMS analysis of methanolic extracts of $D$. muscorum LEGE 12446 cultures supplemented with perdeuterated fatty acids. Shown are EICs for $m / z$ values corresponding to $[\mathrm{M}+\mathrm{H}]^{+}$ions for compound 1 and for hypothesized isotopologues resulting from incorporation of each of the perdeuterated fatty acids. Also shown is Full MS data, highlighting the mass shift supporting incorporation of $d_{11}-C_{6}$ into $\mathbf{1}$. 
Identification and analysis of the $\mathrm{dsm}$ biosynthetic gene cluster. We next looked into the biosynthesis of the desmamides. The structures of 1-3 could, in principle, be reconciled with canonical, hybrid PKS and NRPS biosynthetic logic. This working hypothesis was used to search the genome data of D. muscorum LEGE 12446 (Genbank: JADEXS020000000). Annotation of the genome data using antiSMASH v6.0 $0^{37}$ revealed several hybrid PKS-NRPS BGCs. One such BGC featured two PKS modules upstream of ten NRPS modules, for which the corresponding adenylation (A) domains are predicted select and activate the amino acids that make up the desmamides (Fig. 3A). Notably, these are colinear with the N-to-C termini amino acid sequence of the peptide and contained epimerase (E) domains in the modules predicted to load the experimentally determined D-amino acids. We considered this BGC further as the putative desmamide gene cluster $(\mathrm{dsm})$ and carried out a detailed annotation (Fig. 3A, Table S4) which led us to generate a biosynthetic proposal (Fig. 3B). According to our proposal, the biosynthesis of 1-3 begins with activation of hexanoic acid by an adenylation domain in DsmG, which is related to fatty acyl-AMP ligases (Table S4). This intermediate would then be elongated using malonyl-CoA by the PKS module in DsmG which includes a ketoreductase domain $(\mathrm{KR})$ - to generate a linear 8-carbon beta-hydroxy acyl-ACP intermediate. An additional malonyl-CoA unit would then be used by the PKS module in DsmH to elongate this intermediate to a 10-carbon unit, reduce its beta-keto group (KR domain) and methylate (methyltransferase domain, MT) its alpha position to generate the 11-carbon Dhmda residue. To test the proposed biosynthesis of Dhmda experimentally, in particular whether hexanoic acid $\left(\mathrm{C}_{6}\right)$ is the starter unit for the biosynthesis of 1-3, we supplemented D. muscorum LEGE 12446 cultures with perdeuterated fatty acids, namely hexanoic $\left(d_{11}-\mathrm{C}_{6}\right)$, octanoic $\left(d_{15^{-}}\right.$ $\left.\mathrm{C}_{8}\right)$ and decanoic $\left(d_{19}-\mathrm{C}_{10}\right)$ acids. LC-HRESIMS analysis showed that only $d_{11}-\mathrm{C}_{6}$ was incorporated into 1-3 (Fig. $3 \mathrm{C}$ ), indicating that hexanoic acid is a substrate in the biosynthesis of the desmamides, as hypothesized. However, we could not find any ACP domain in between the adenylation domain proposed to load hexanoic acid and the first PKS module, which is unusual. A KR domain downstream of the A domain in DsmG is of the C-1 type, and therefore inactive. ${ }^{38}$ The PKS module of DsmG includes a DH domain, containing all catalytical residue (as per antiSMASH analysis), which does not seem necessary to generate the Dhmda residue of 1-3. As per our proposal and canonical hybrid PKS/NRPS biosynthesis ${ }^{39}$, the resulting $\mathrm{C}_{11}$ acyl intermediate is passed to the first NRPS module in DsmI which loads Gln, followed by incorporation of the additional amino acids into the growing chain by the NRPS machinery encoded in DsmI and DsmJ. Finally, the thioesterase in the Cterminus of DsmJ would catalyze the concomitant cyclization and chain release of the desmamides (Fig. 3A,B).

Intriguingly, despite $\mathbf{1}$ and $\mathbf{2}$ being glycosylated, we could not find a glycosyltransferase-encoding gene in the $d s m$ locus or its genomic neighborhood. A genome-wide search for GTs, in particular those known to glycosylate tyrosine residues in the biosynthesis of natural products, indicated multiple GTs, some of which were lowidentity homologs of the cacaoidin BGC GTs (Table S5), however none was near the $d s m$ locus. Homologs of the mannopeptimycin glycosyltransferases ${ }^{40}$ were not detected in our searches. It is also unclear if any of the $d s m$ BGC-encoded enzymes is responsible for the 4-O-acetylation of the sugar residue. One possibility would be the predicted acyltransferase DsmD. Enzymes containing a GNATlike fold such as DsmD (which contains two GNAT-like domains) are known to $N$-acylate several substrates ${ }^{41}$ but have also been reported to catalyze $O$-acetylation of sugar residues. ${ }^{42,43}$ Interestingly, hassallidins also feature $O$-acetylation in sugar residues decorating the peptide. In this case, the authors suggested that HasR, an acyltransferase encoded in the hassallidin (has) BGC could be responsible for these decorations. ${ }^{20}$ We were unable to detect any homologs of HasR in the genome of D. muscorum LEGE 12446.

Hassallidins are widely distributed among the Nostocales. ${ }^{20} \mathrm{We}$ wondered if this was the case for desmamides and whether $d s m$ like BGCs could be found in genomes of cultured cyanobacteria or in metagenome data. The ClusterBlast tool in antiSMASH could not retrieve any similar BGCs and BlastP searches (nr/env_nr databases) using DsmG/DsmH/DsmI/DsmJ amino acid sequences as query did not retrieve hits with a genomic context that would configure a full $d s m$ BGC. Curiously, several Dsm proteins have a very high identity to homologs from Nostoc sp. FACHB-973 and Desmonostoc muscorum CCALA 125 (Table S4). Because such homologs are present in more than one contig in each of the genome assemblies, it is unclear if these are part of $d s m$ BGCs.

Table 2 - Biological activity of compounds $\mathbf{1}$ and $\mathbf{2}$. IC $C_{50}$ values are in $\mu \mathrm{M}$.

\begin{tabular}{|c|c|c|c|c|c|c|c|c|}
\hline \multirow[b]{2}{*}{ compound } & \multicolumn{7}{|c|}{ Cytotoxicity, $\mathrm{IC}_{50}$} & \multirow{2}{*}{$\frac{\text { Antibacterial, } \mathrm{IC}_{50}}{\text { X. campestris }}$} \\
\hline & $\mathrm{HaCaT}$ & A-375 & A-549 & HCT-116 & $\begin{array}{c}\text { MDA-MB- } \\
231\end{array}$ & HepG2 & HT-29 & \\
\hline 1 & $>100$ & $>100$ & $51.6 \pm 0.6$ & $>100$ & $44.6 \pm 0.3$ & $>100$ & $>100$ & $46.5 \pm 1.1$ \\
\hline 2 & $44.1 \pm 8.3$ & $43.8 \pm 0.3$ & $43.3 \pm 0.3$ & $57.0 \pm 9.7$ & $27.9 \pm 2.0$ & $40.7 \pm 1.4$ & $41.6 \pm 0.7$ & $33.7 \pm 4.3$ \\
\hline control $^{a}$ & $19.3 \pm 0.4$ & $8.8 \pm 4.2$ & $6.1 \pm 0.7$ & $63.3 \pm 9.0$ & $12.9 \pm 0.7$ & $4.6 \pm 1.3$ & $2.2 \pm 0.2$ & $2.0 \pm 0.1$ \\
\hline
\end{tabular}

${ }^{a}$ Positive controls: doxorubicin (cancer cell line cytotoxicity assays) or chloramphenicol (antibacterial assays). 
Biological activity. Compounds $\mathbf{1}$ and $\mathbf{2}$ were tested against a panel of human cancer cell lines, namely liver cancer cell line HepG2, colorectal adenocarcinoma cell line HT-29, malignant melanoma cell line A-375, colon cancer cell line HCT-116, lung carcinoma cell line A-549, breast cancer line MDA-MB-231 as well as the non-cancerous keratinocyte line HaCaT. As shown in Table 2, all compounds showed weak cytotoxicity. Compound 1 moderately inhibited the growth of two tumor cell lines A-549 and MDA-MB231, whereas 2 was active against all cancer cell lines with slightly higher potency. The strongest cytotoxicity was exerted by 2 against MB-231 cells with $\mathrm{IC}_{50}$ value of $27.9 \mu \mathrm{M}$. However, 2 displayed toxicity against the $\mathrm{HaCaT}$ cell line with $\mathrm{IC}_{50}$ values similar to those observed against the cancer cell lines, indicating its general toxicity. Both 1 and 2 were tested against a wide variety of gram positive and gram negative bacterial and fungal pathogens. They showed no inhibitory activity at the standard concentration of 100 $\mu \mathrm{g} \mathrm{mL} \mathrm{m}^{-1}$ except a moderate activity against the plant pathogenic bacterium Xanthomonas campestris with IC50 values of $48.2 \mu \mathrm{M}$ and $33.7 \mu \mathrm{M}$, respectively.

\section{Conclusions}

In this study, we have explored a cycad coralloid root symbiotic cyanobacterium for its novel secondary metabolites. This resulted in isolation and structure elucidation of the new lipoglycopeptides $\mathbf{1}$ and $\mathbf{2}$ and their aglycone $\mathbf{3}$. We proposed that the $d s m$ BGC is involved in the biosynthesis of these compounds. Desmamides feature an unprecedented type of fatty acyl moiety among lipopeptides, which is derived from a hexanoic acid starter unit. While the enzyme functions predicted to be encoded in the $d s m$ BGC are congruent with the formation of $\mathbf{3}$ and, therefore, the aglycones of $\mathbf{1}$ and 2 , it was not possible to rationalize the glycosylating enzyme(s) through bioinformatics predictions. The desmamides expand the diversity of natural lipoglycopeptides, a small group of natural products with remarkable antibacterial and antifungal properties. We explored the biological activity of the desmamides and found that these were only weakly active towards several different human cancer cell lines. However, compound $\mathbf{2}$ showed considerable antibiotic potency towards the black rot disease-causing plant pathogen Xanthomonas campestris. Lipopeptides and lipoglycopeptides often have important antibacterial activities. ${ }^{17,44}$ Given their abundance in D. muscorum LEGE 12446, high concentrations of desmamides are likely to occur in a natural setting and could potentially be related to a defensive ecological role in its host plant. This will necessarily involve studying the potential production of 1-3 inside the coralloid roots. For example, two Nostoc sp. coralloid root endosymbionts, isolated from Macrozamia spp. cycads, were found to produce the toxin nodularin in planta. ${ }^{45}$ Overall, the discovery of the desmamides and of the $d s m$ BGC sets the foundation exploring the role of these very abundant $(1.6 \%$ d.w.) metabolites, in particular in the context of cycad coralloid root symbiosis. Despite all the recent progress in understanding the secondary metabolism of the facultative endosymbiont Nostoc punctiforme PCC 73102, ${ }^{46}$ these systems are still poorly understood in terms of chemical ecology. ${ }^{47}$

\section{Methods}

\section{General experimental procedures}

Optical rotations were measured using a JASCO P-2000 polarimeter (JASCO) with SpectraManager 2.14.02 software. Infrared spectra were collected on a Nicolet iS5 FTIR spectrometer (ThermoScientific) with OMNIC 9.8.372 software. The UV spectra were acquired on a UV-1600PC spectrometer (VWR) controlled by MWAVE 1.0.20 software. 1D and 2D NMR data were obtained in the Materials Center of the University of Porto (CEMUP) on a Bruker Avance III, $400 \mathrm{MHz}$ controlled by TopSpin 3.2. Compounds were analyzed in deuterated DMSO (DMSO-d6, Sigma). Chemical shifts $\left({ }^{1} \mathrm{H}\right.$ and $\left.{ }^{13} \mathrm{C}\right)$ are expressed in $\delta(\mathrm{ppm})$, referenced to the residual non-deuterated solvent used. NMR data were analyzed in MNova 12.0.4. LC-HRESIMS and LC-HRESIMS/MS analyses were performed on an UltiMate 3000 UHPLC (Thermo Fisher Scientific) system composed of a LPG-3400SD pump, WPS-3000SL autosampler and VWD-3100 UV/VIS detector coupled to a Q Exactive Focus Hybrid Quadrupole-Orbitrap Mass Spectrometer controlled by Q Exactive Focus Tune 2.9 and Xcalibur 4.1 (Thermo Fisher Scientific). For LC-HRESIMS data, Full Scan mode was used with capillary voltage set to $-3.8 \mathrm{kV}$, capillary temperature to $300^{\circ} \mathrm{C}$ and sheath gas flow rate to 35 units. HPLC separations were performed in a JASCO PU-4180 HPLC pump with MD-4010 Photo Diode Array Detector (JASCO) and separations were monitored at $254 \mathrm{~nm}$ wavelength. All solvents used were ACS grade, except for HPLC solvents (HPLC gradient grade) and LC-MS solvents (MS-grade). Stable-isotope labeled fatty acids ( $\mathrm{d}_{11}$-hexanoic, $\mathrm{d}_{15}$-octanoic and $\mathrm{d}_{19}$-decanoic and $\mathrm{d}_{23}$-dodecanoic were obtained from CDN Isotopes Inc, amino acids were purchased from Fluorochem (D-allo-Thr; L-allo-Thr; D-Ser; L-Ser; L-Val; D-Val; L-Pro; D-Pro; D-Tyr; L-Tyr; D-Leu; L-Leu; D-Thr), Alfa Aesar (D-Gln) and Glenthan Life Sciences (L-Gln; L-Thr). Monosaccharide standards were acquired from Sigma Aldrich (D-xylose; L-arabinose), Alfa aesar (D-ribose; D-arabinose) and Acros Organics (L-ribose). The reagents 3-Methyl-1-phenyl-2-pyrazoline-5-one (PMP) was obtained from Alfa Aesar and Na-(2,4-Dinitro-5fluorophenyl)-L-alaninamide (Marfey's reagent) were purchased from Sigma Aldrich.

\section{Cyanobacterial strain cultivation}

The cyanobacterial strain Desmonostoc muscorum LEGE 12446, kindly provided by LEGEcc, ${ }^{26}$ was cultured in $\mathrm{Z} 8$ media, at $25^{\circ} \mathrm{C}$, with constant aeration, under a $14 \mathrm{~h} / 10 \mathrm{~h}$ light $\left(10-30 \mu \mathrm{mol}\right.$ photons $\left.\mathrm{s}^{-1} \mathrm{~m}^{-2}\right) /$ dark cycle. Large-scale culturing of this strain was carried out in $80 \mathrm{~L}$ low-density polyethylene sleeves for a total of $160 \mathrm{~L}$ and cells were harvested during late exponential/early stationary phase through centrifugation $(7178 \times g)$, immediately frozen and freeze-dried until further usage.

\section{Molecular Networking Analysis}

The cyanobacterial strain D. muscorum LEGE 12446 was analyzed using GNPS Molecular Networking analysis. ${ }^{27}$ Briefly, $4 \mathrm{~L}$ of culture were harvested at the exponential phase of growth, frozen and freeze-dried. A crude extraction of the dry cell material using a mixture of $\mathrm{CH}_{2} \mathrm{Cl}_{2} / \mathrm{MeOH}(2: 1$, $\mathrm{v} / \mathrm{v})$ was performed at room temperature and the resulting extract was fractionated in a Strata SI-1 Silica cartridge $(5 \mathrm{~g}, 55 \mu \mathrm{m}, 70 \mathrm{~A}$, Phenomenex) using a gradient of increasing polarity from $n$-hexane ( $n$-hex) to EtOAc to $\mathrm{MeOH}$, to yield three fractions (A-C). For LC-HRESIMS analysis, fractions were prepared at $1.0 \mathrm{mg} \mathrm{mL}^{-1}$ in LC-MS grade $\mathrm{MeOH}$, filtered through a $0.2 \mu \mathrm{m}$ syringe regenerated cellulose filter, and $5 \mu \mathrm{L}$ were injected in an ACE Ultracore 2.5 SuperC18 column $(75 \times 2.1 \mathrm{~mm})$. Samples were eluted at $0.35 \mathrm{~mL} \mathrm{~min}^{-1}$ over a linear gradient from $99.5 \%$ solution $\mathrm{A}\left(95 \% \mathrm{H}_{2} \mathrm{O}\right.$, 
$5 \% \mathrm{MeOH}, 0.1 \% \mathrm{v} / \mathrm{v} \mathrm{HCOOH}$ ) and $0.5 \%$ solution B (95\% isopropanol, $5 \%$ $\mathrm{MeOH}, 0.1 \% \mathrm{v} / \mathrm{v} \mathrm{HCOOH}$ ) to reach $10 \%$ solution B over 0.5 min, followed by an increase to $60 \%$ solution B in $8 \mathrm{~min}$ and then to $90 \%$ in $1 \mathrm{~min}$; these conditions were kept for $6 \mathrm{~min}$ before returning to the initial conditions. The column oven was set to $40^{\circ} \mathrm{C}$, UV monitoring was carried out at $254.0 \mathrm{~nm}$. The capillary voltage of the Heated Electrospray Ionization (HESI) was set to $3.8 \mathrm{kV}$ and its temperature to $300{ }^{\circ} \mathrm{C}$. The sheath gas and auxiliary gas flow rate were at 35 and 10 (arbitrary units as provided by the software settings). Full MS scans were acquired at a resolution of 70,000 FWHM (range of $150-2000 \mathrm{~m} / \mathrm{z}$ ), and data dependent MS/MS (ddMS ${ }^{2}$, Discovery mode) at a resolution of 17,500 FWHM (isolation window used was 3.0 amu and normalized collision energy was 35 ). For the molecular network analysis, the protocol available in GNPS documentation was followed and the resulting network file was visualized using Cytoscape v3.8.0.

\section{Extraction and Isolation of 1-3}

Freeze-dried biomass from large-scale culturing (70.3 g, d.w.) was extracted by repeated percolation using a mixture of $\mathrm{CH}_{2} \mathrm{Cl}_{2} / \mathrm{MeOH}(2: 1, \mathrm{v} / \mathrm{v})$ at room temperature and at $40{ }^{\circ} \mathrm{C}$. A total extract mass of $14.7 \mathrm{~g}$ was obtained. Further fractionation using vacuum liquid chromatography (VLC) was performed, using silica gel $60(0.015-0.040 \mathrm{~mm}$, Merck). The extract was dry loaded onto the column using $15 \mathrm{~g}$ of silica. A mixture of $1: 1(\mathrm{v} / \mathrm{v})$ EtOAc/ $n$-hex was used to start the separation and stepwise gradient to $100 \%$ EtOAc and then to $100 \% \mathrm{MeOH}$ was used, yielding 13 fractions. Fractions containing the mass features of interest (eluting with 2:3 (v/v) to 3:7 (v/v) EtOAc/MeOH) were further fractionated using flash chromatography (silica gel 60, 0.040-0.063 mm, Merck), with a stepwise gradient from 1:1 (v/v) EtOAc/MeOH to $100 \% \mathrm{MeOH}$, yielding 7 fractions. The mass features of interest were present in fractions 2-4, which were pooled and further separated by reversed-phase solid phase extraction (SPE) in a Strata C18-E cartridge $(50 \mathrm{~g}, 55 \mu \mathrm{m}, 70 \mathrm{~A}$, Phenomenex) using a stepwise gradient from $5 \%$ $\mathrm{MeOH}$ (aq) (solution A) to 95\% IPA with 5\% MeOH (solution B), yielding a total of 11 fractions. The first fraction (A, $565 \mathrm{mg}$ ), eluting with $5 \%$ $\mathrm{MeOH}$ (aq), was selected for reversed phase semi-preparative HPLC separation using a $\mathrm{C} 18$ column (100 $\AA, 250 \times 10 \mathrm{~mm}, 5 \mu \mathrm{m}$, ACE). A gradient elution program was employed, starting with $35 \% \mathrm{MeCN}$ (aq), increasing to $60 \% \mathrm{MeCN}(\mathrm{aq}$ ) over $20 \mathrm{~min}$, and then to $100 \% \mathrm{MeCN}$ in $5 \mathrm{~min}$, before returning to the initial conditions. Fraction A2 (33.5 mg, $\left.\mathrm{t}_{\mathrm{R}} 8-9 \mathrm{~min}\right)$ was collected and subjected to an additional purification step in the same system but with a gradient starting in $35 \% \mathrm{MeCN}$ (aq) and increasing to $46 \%$ $\mathrm{MeCN}$ (aq) in $15 \mathrm{~min}$, and then to $100 \% \mathrm{MeCN}$ in $5 \mathrm{~min}$ before returning to the initial conditions. This purified fraction A2 corresponded to spectroscopically pure desmamide A (compound $1, t_{R}=10.0 \mathrm{~min}, 26.3 \mathrm{mg}$ ). HPLC fraction A5 (5.8 mg, $\left.\mathrm{t}_{\mathrm{R}}=11-13 \mathrm{~min}\right)$ corresponded to partially purified desmamide $\mathrm{C}$ and was further separated by semi-preparative reversed phase HPLC with an Aeris Peptide XB-C18 column (100 $\AA, 250 \times 10 \mathrm{~mm}, 5 \mu \mathrm{m}$, Phenomenex). A gradient from $35 \% \mathrm{MeCN}$ (aq) to $45 \% \mathrm{MeCN}$ (aq) in 22 min was applied to yield spectroscopically pure desmamide $\mathrm{C}\left(\mathbf{3}, \mathrm{t}_{\mathrm{R}}=15.5\right.$ min, $4.0 \mathrm{mg}$ ). Desmamide B (2) was purified from SPE fraction E (977 mg), eluting with $3: 2(\mathrm{v} / \mathrm{v})$ of a mixture of solution $\mathrm{A}(5 \% \mathrm{MeOH}(\mathrm{aq}))$ and solution B (IPA with 5\% MeOH), following semi-preparative HPLC using an Aeris Peptide XB-C18 column ( $100 \AA \AA, 250 \times 10$ mm, $5 \mu \mathrm{m}$, Phenomenex). The separation was carried out with isocratic $35 \% \mathrm{MeCN}(\mathrm{aq})$ for $16 \mathrm{~min}$, and then a linear gradient to $50 \% \mathrm{MeCN}$ (aq) in $3 \mathrm{~min}$, before returning to the initial conditions. Only $205 \mathrm{mg}$ of sample (fraction E) were processed. Fraction E6 corresponded to spectroscopically pure desmamide B (2, $\mathrm{t}_{\mathrm{R}}=18.0 \mathrm{~min}, 20.4 \mathrm{mg}$ ).
Desmamide A (1). Amorphous white powder; $[\alpha]_{\mathrm{D}}^{23}+41(c 0.01, \mathrm{MeOH})$; IR $v_{\max } 3271.3,2954.5,2929.6,2929.6,2871.3,2350.9,2317.8,1738.7$, 1733.1, 1667.3, 1660.5, 1651.6, 1645.3, 1634.5, 1574.4, 1557.3, 1548.6, 1539.0, 1532.4, 1511.6, 1455.34, $1417.9 \mathrm{~cm}^{-1}$; UV (MeOH) $\lambda_{\max }(\log \varepsilon)$ 219.0 (3.2), 272.0 (2.9), 278.5 (2.8); ${ }^{1} \mathrm{H}$ and ${ }^{13} \mathrm{C}$ NMR spectroscopic data (DMSO- $d_{6}$ ) Table 1; HRESIMS $\mathrm{m} / z 1388.7577[\mathrm{M}+\mathrm{H}]^{+}$(calcd. for $\mathrm{C}_{66} \mathrm{H}_{106} \mathrm{~N}_{11} \mathrm{O}_{21}$ 1388.7559); HRESIMS/MS (Fig. S13).

Desmamide B (2). Amorphous white powder; $[\alpha]_{\mathrm{D}}^{23}+37(c 0.01, \mathrm{MeOH})$; IR $\gamma_{\max } 3271.2,2953.9,2928.9,2870.3,2351.0,2327.9,1737.9,1732.6$, $1667.0,1660.1,1651.4,1645.0,1634.3,1574.1,1556.9,1548.2,1538.5$, $1532.2,1511.5,1462.8,1417.6 \mathrm{~cm}^{-1}$; UV $(\mathrm{MeOH}) \lambda_{\max }(\log \varepsilon) 222.0(3.2)$, 272.0 (2.9), 278.5 (2.8); ${ }^{1} \mathrm{H}$ and ${ }^{13} \mathrm{C}$ NMR spectroscopic data (DMSO- $d_{6}$ ) Table S3; HRESIMS $m / z 1430.7666[\mathrm{M}+\mathrm{H}]^{+}$(calcd. for $\mathrm{C}_{68} \mathrm{H}_{108} \mathrm{~N}_{11} \mathrm{O}_{22}$ 1430.7665); HRESIMS/MS (Fig. S27).

Desmamide C (3). Amorphous white powder; $[\alpha]_{\mathrm{D}}^{23}+10(c 0.01, \mathrm{MeOH})$; IR $v_{\max } 3270.6,2955.9,2929.2,2871.2,2350.8,1660.2,1651.3,1538.6$, $1515.9,1447.3 \mathrm{~cm}^{-1}$; UV (MeOH) $\lambda_{\max }(\log \varepsilon) 231.0$ (3.2), 277.5 (3.1); ${ }^{1} \mathrm{H}$ and ${ }^{13} \mathrm{C}$ NMR spectroscopic data (DMSO- $d_{6}$ ) Figure S21-S22; HRESIMS $m / z \quad 1256.7149 \quad[\mathrm{M}+\mathrm{H}]^{+} \quad$ (calcd. for $\mathrm{C}_{61} \mathrm{H}_{98} \mathrm{~N}_{11} \mathrm{O}_{17} \quad$ 1256.7142); HRESIMS/MS (Fig. S28)

\section{HRESIMS/MS analysis}

HRESIMS/MS analysis of pure 1-3 was performed by direct injection of each compound $\left(1.0 \mathrm{mg} \mathrm{mL}^{-1}\right.$, flow $\left.0.005 \mathrm{~mL} \mathrm{~min}^{-1}\right)$ into the spectrometer, with a 35,000 FWHM resolution, using an isolation window of $1 \mathrm{~m} / \mathrm{z}$, loop count of 3 and AGC target of $5 \times 10^{4}$ and a collision energy of 60 (arbitrary unit).

\section{Quantification of desmamides in D. muscorum LEGE 12446}

To quantify the production of desmamides in the cyanobacterial $D$. muscorum LEGE 12446, a calibration curve for each compound was obtained from LC-HRESIMS analysis. Briefly, desmamide A-C standards were prepared at $0.5 \mathrm{mg} \mathrm{mL}^{-1}, 0.1 \mathrm{mg} \mathrm{mL}^{-1}, 0.05 \mathrm{mg} \mathrm{mL}^{-1}, 0.01 \mathrm{mg} \mathrm{mL}^{-1}, 0.005 \mathrm{mg}$ $\mathrm{mL}^{-1}$ and $0.001 \mathrm{mg} \mathrm{mL}^{-1}$. Five-microliters $(5 \mu \mathrm{L})$ of each standard solution were injected in an LC-HRESIMS system fitted with an ACE Ultracore 2.5 SuperC18 column $(75 \times 2.1 \mathrm{~mm})$ following the same chromatographic and spectrometric conditions described in the molecular networking analysis method. The area under the curve from the extracted ion chromatograms (EIC) for each compound were plotted $\left(0.1 \mathrm{mg} \mathrm{mL}^{-1}\right.$ to $\left.0.001 \mathrm{mg} \mathrm{mL}^{-1}\right)$ and a linear regression was fitted. This was then used to extrapolate the concentration of each compound in the initial crude extract used for isolation and in the biomass from which it was obtained (Table S2, Fig. S3).

\section{Chiral-Phase HPLC}

For the acid hydrolysis of $1,1.5 \mathrm{mg}$ of compound was placed into $1.0 \mathrm{~mL}$ of $6 \mathrm{~N} \mathrm{HCl}$ for $24 \mathrm{~h}$ at $110^{\circ} \mathrm{C}$ under continuous stirring. After the reaction, $\mathrm{HCl}$ was removed under a $\mathrm{N}_{2}$ stream. Amino acids standards (proline, valine, leucine, tyrosine), $\mathrm{L}$ - and $\mathrm{D}$ - isomers were prepared at $0.5 \mathrm{mg} \mathrm{mL}^{-1}$ with MS-grade $\mathrm{H}_{2} \mathrm{O}$. The hydrolysate of 1 was prepared $1.0 \mathrm{mg} \mathrm{mL}^{-1}$ with MS-grade $\mathrm{H}_{2} \mathrm{O}$. A volume of $10 \mu \mathrm{L}$ of each sample was injected onto the HPLC system and separated in a Chirex 3126 (D)-penicillamine column (50 $\times 4.6 \mathrm{~mm}$, Phenomenex), using a $1 \mathrm{mM} \mathrm{CuSO} / \mathrm{H}_{2} \mathrm{O}$ solution as mobile phase, at a $1.0 \mathrm{~mL} \mathrm{~min}^{-1}$ flow rate. To confirm the absolute configuration of the amino acids, co-injection of the hydrolysate with both versions of each amino acid standard ( $15 \mu \mathrm{L}+5 \mu \mathrm{L}$, respectively) was performed. Retention time $\left(\mathrm{t}_{\mathrm{R}}, \mathrm{min}\right)$ for standards: L-Pro 4.7, D-Pro 9.7, L-Val 6.4, D-Val 
11.1, L-Leu 21.3, D-Leu 34.5, L-Tyr 24.0 and D-Tyr 43.8. Retention time $\left(\mathrm{t}_{\mathrm{R}}, \mathrm{min}\right)$ for hydrolysate: L-Pro 4.4, L-Val 5.9, D-Leu 32.5 and D-Tyr 42.3.

\section{Marfey's Derivatization Analysis}

The Marfey's derivatization method was used to assign the configuration of Ser, Gln, Thr, and allo-Thr residues. L- and D- isomer standards of each amino acid were prepared at $50 \mathrm{mM}$ in $50 \mu \mathrm{L}$ of LC-MS grade $\mathrm{H}_{2} \mathrm{O}$. A Marfey's reagent (1-fluoro-2,4-dinitrophenyl-5-L-alanine amide) solution was prepared at a $1 \%(\mathrm{w} / \mathrm{v})$ concentration in $100 \mu \mathrm{L}$ acetone. For hydrolysate $(0.6 \mathrm{mg}$, obtained as for the chiral HPLC analysis) derivatization, 100 $\mu \mathrm{L}$ of $1 \mathrm{M} \mathrm{NaHCO}_{3}$ and $100 \mu \mathrm{L}$ of the Marfey's reagent acetone solution were added to a glass vial, which was placed on an oil bath at $40{ }^{\circ} \mathrm{C}$ for $1 \mathrm{~h}$ with a magnetic stirrer. The reaction was quenched with $100 \mu \mathrm{L}$ of $1 \mathrm{M} \mathrm{HCl}$, diluted with $200 \mu \mathrm{L} \mathrm{MeCN}$ (LC-MS grade) and filtered $(0.2 \mu \mathrm{m})$. The same protocol was applied to the amino acids standards: to $50 \mu \mathrm{L}$ of each standard it was added $20 \mu \mathrm{L}$ of $1 \mathrm{M} \mathrm{NaHCO} 3$ and $100 \mu \mathrm{L}$ of the Marfey's reagent solution. The reaction $\left(40^{\circ} \mathrm{C}, 1 \mathrm{~h}\right)$ was quenched with $20 \mu \mathrm{L} 1 \mathrm{M} \mathrm{HCl}$ and diluted with $810 \mu \mathrm{L} \mathrm{MeCN}$. After derivatization all samples were analyzed by LC-HRESIMS, using an ACE UltraCore 2.5 SuperC18 column $(75 \times 2.1$ $\mathrm{mm}$, Avantor). Eluents were solutions A $\left(95 \% \mathrm{H}_{2} \mathrm{O}, 5 \% \mathrm{MeOH}, 0.1 \% \mathrm{v} / \mathrm{v}\right.$ $\mathrm{HCOOH})$ and $\mathrm{B}(95 \% \mathrm{IPA}, 5 \% \mathrm{MeOH}, 0.1 \% \mathrm{v} / \mathrm{v} \mathrm{HCOOH})$. The separation was carried out as follows: $100 \%$ A for $1 \mathrm{~min}$, then a linear gradient for 7 min to $60 \% \mathrm{~B}$ and then a steeper gradient to $100 \% \mathrm{~B}$ in $1 \mathrm{~min}$ and held at $100 \% \mathrm{~B}$ for $2 \mathrm{~min}$ before returning to the initial conditions. Injection volume was $10 \mu \mathrm{L}$. Retention time ( $\mathrm{t}_{\mathrm{R}}, \mathrm{min}$ ) for standards: L-Ser 7.29, D-Ser 7.35, L-Leu 12.04, D-Leu 13.61, L-Thr 10.29, D-Thr 16.84, L-allo-Thr 10.50, D-allo-Thr 12.87, L-Gln 9.88, D-Gln 10.52. Retention time $\left(t_{R}, \min \right)$ for hydrolysate: L-Ser 7.29, D-Leu 13.62, L-Thr 10.23, L-Gln 9.26.

\section{Feeding experiments with perdeuterated fatty acids}

To study the putative incorporation of a fatty acid unit in desmamide A, supplementation of Desmonostoc muscorum LEGE 12446 with a series of deuterium-labelled fatty acids: $d_{11}$-hexanoic acid ( $d_{11}$-C6), $d_{15}$-octanoic acid $\left(d_{15}\right.$-C8), $d_{19}$-decanoic acid $\left(d_{19}\right.$-C10) and $d_{23}$-dodecanoic acid $\left(d_{23}-\mathrm{C} 12\right)$ was carried out. Stock solutions of the labelled fatty acids were prepared in DMSO (500 mM). Small-scale cultures $(25 \mathrm{~mL})$ growing in $\mathrm{Z} 8$ medium were supplemented by pulse feeding (three times, two-day interval) with $8.33 \mu \mathrm{L}$ of deuterated fatty acid stock solution, to a final concentration of $0.5 \mathrm{mM}$. A control experiment with non-deuterated hexanoic acid (C6) was performed. Experiments were carried out in duplicate. Cultures are placed in the same growth conditions described above with shaking in an orbital shaker at $200 \mathrm{rpm}$. After 7 days, cells were harvested by centrifugation, the pellet rinsed with ddH2O and extracted with $15 \mathrm{~mL}$ of a mixture of $\mathrm{CH}_{2} \mathrm{Cl}_{2} / \mathrm{MeOH}(2: 1, \mathrm{v} / \mathrm{v})$ in an orbital shaker for $30 \mathrm{~min}$. The extracts were then filtered, dried under vacuum and resuspended in $\mathrm{MeOH}$ for LCHRESIMS analysis $\left(2 \mathrm{mg} \mathrm{mL}^{-1}\right)$. Samples were separated in an ACE UltraCore SuperC18 $(2.5 \mu \mathrm{m}, 95 \AA, 75 \times 2.1 \mathrm{~mm})$ column. Elution was performed with a $0.4 \mathrm{~mL} \mathrm{~min}^{-1}$ flow using mixtures of eluents $\mathrm{A}\left(\mathrm{H}_{2} \mathrm{O} / \mathrm{MeOH} 1: 1\right.$, $0.1 \% \mathrm{v} / \mathrm{v} \mathrm{HCOOH}$ ) and $\mathrm{B}$ (IPA, $0.1 \% \mathrm{v} / \mathrm{v} \mathrm{HCOOH})$. The following program was applied: isocratic $10 \% \mathrm{~B}$ for $1 \mathrm{~min}$, then a linear gradient to $65 \% \mathrm{~B}$ over $5 \mathrm{~min}$, holding at $65 \% \mathrm{~B}$ for $12 \mathrm{~min}$ before increasing to $85 \%$ B over $2 \mathrm{~min}$ and holding again for $9 \mathrm{~min}$ at $85 \% \mathrm{~B}$ before returning to the initial conditions. The column oven was set to $40{ }^{\circ} \mathrm{C}$, data was obtained in Full Scan (switching mode), with a capillary voltage of HESI $+3.5 \mathrm{kV} /-3.8 \mathrm{kV}$ and a capillary temperature of $300{ }^{\circ} \mathrm{C}$.

\section{Monosaccharide derivatization analysis with PMP}

To determine the identity of the sugar residue in $\mathbf{1}$, we used a sugar derivatization method using 1-phenyl-3-methyl-5-pyrazolone (PMP) to allow for HPLC-based determination of monosaccharides. ${ }^{48}$ Some adaptations to the published method were made. Briefly, monosaccharide standards (D-arabinose, D-xylose and D-ribose) were prepared at $0.5 \mathrm{mg} \mathrm{mL}^{-1}$ with LC-MS grade $\mathrm{H}_{2} \mathrm{O}$. To $100 \mu \mathrm{L}$ of each sugar solution, it was added $100 \mu \mathrm{L}$ of $0.3 \mathrm{M}$ $\mathrm{NaOH}$ and $100 \mu \mathrm{L}$ of PMP reagent $(0.5 \mathrm{M}$ in $\mathrm{MeOH})$. Reaction mixtures were placed in an oil bath at $70{ }^{\circ} \mathrm{C}$ for $30 \mathrm{~min}$. The mixtures were then quenched with $100 \mu \mathrm{L} 0.3 \mathrm{M} \mathrm{HCl}$ and dried in a rotatory evaporator. Equal volumes of $\mathrm{H}_{2} \mathrm{O}$ and $\mathrm{CHCl}_{3}(1 \mathrm{~mL})$ were added to extract the PMP residues. The organic layer was discarded and this process was repeated twice by adding $\mathrm{CHCl}_{3}$ to the aqueous layer. Finally, the aqueous layer was dried and dissolved using $1 \mathrm{~mL}$ LC-MS grade $\mathrm{H}_{2} \mathrm{O}$. The same protocol was applied to $0.5 \mathrm{mg}$ of the hydrolysate of 1 , which was dissolved in $0.5 \mathrm{~mL}$ of LC-MS grade $\mathrm{H}_{2} \mathrm{O}$. For monosaccharide derivatives analysis, an LC-HRESIMS run was performed, using a ACE UltraCore SuperC18 $(2.5 \mu \mathrm{m}, 95 \AA, 75 \times 2.1$ $\mathrm{mm}$ ) column and the elution was carried out isocratically with a $83: 17, \mathrm{v} / \mathrm{v}$ mixture of $\mathrm{H}_{2} \mathrm{O}$ with $0.1 \% \mathrm{v} / \mathrm{v} \mathrm{HCOOH}$ and $\mathrm{MeCN}$ with $0.1 \% \mathrm{v} / \mathrm{v} \mathrm{HCOOH}$, respectively. The flow rate used was $0.4 \mathrm{~mL} \mathrm{~min}^{-1}, 5 \mu \mathrm{L}$ of each derivative monosaccharide and hydrolysate solution were injected for analysis and the separation was monitored using a wavelength of $245 \mathrm{~nm}$. The column oven was set to $30^{\circ} \mathrm{C}$. - Retention time ( $t_{R}, \mathrm{~min}$ ) for standards: ribose 5.1, arabinose 10.7 , xylose 11.5 . Retention time $\left(t_{R}, \mathrm{~min}\right)$ for hydrolysate: arabinose 10.7 (minor), xylose 11.4 (major).

\section{Genome sequencing and bioinformatics analysis}

The cyanobacterium D. muscorum LEGE 12446 was sequenced through a specialized sequencing service (enhanced genome service) provided by the company MicrobesNG, using a combination of short-read Illumina and long-read Nanopore sequencing technologies. Fresh biomass, harvested after 15 days' cultivation period, were sent to the service provider. Following gDNA extraction and sequencing, raw data was submitted to a bioinformatics pipeline. Briefly, identification of the closest reference genomes for reading mapping was done using Kraken $2,{ }^{49}$ BWA-MEM was used to check the quality of the reads and de novo assembly was performed using SPAdes. ${ }^{50}$ Since the culture was not axenic, the genomic data was treated as a metagenome: the retrieved contigs were analyzed using the binning tool MaxBin 2.0., ${ }^{51}$. This procedure yielded a nearly complete genome (Genbank: JADEXS020000000) with an estimated size of $9.64 \mathrm{Mb}$, distributed among 12 contigs. AntiSMASH v6. $0^{37}$ was used to annotate biosynthetic gene clusters (BGCs) in the genome data using relaxed detection settings and all extra features selected. Manual annotation and searches for enzyme homologs in the genome of D. muscorum LEGE 12446 were performed using BlastP or tBlastn.

\section{Cell viability assay}

The sensitivity of malignant melanoma cell line A-375 (CLS, Eppelheim, Germany), colon cancer cell line HCT-116 (DSMZ, Braunschweig, Germany), lung carcinoma cell line A-549 (CLS, Eppelheim, Germany), human breast cancer line MDA-MB-231 (CLS, Eppelheim, Germany) and the noncancerous human keratinocyte line HaCaT (CLS, Eppelheim, Germany) to the samples was evaluated by monitoring the metabolic activity using the CellTiterBlue Cell Viability Assay (Promega, Mannheim, Germany). HaCaT cells were cultivated in RPMI medium, A549 and MDA-MB-231 cells in DMEM:Ham's F12 medium (1:1) supplemented with 15 mM HEPES and A-375 and HCT-116 cells in DMEM medium supplemented with 4.5 $\mathrm{g} \mathrm{L}^{-1} \mathrm{D}$-Glucose and $110 \mathrm{mg} \mathrm{L}^{-1}$ Sodium Pyrovate. All media were supplemented with L-Glutamine, $10 \%$ fetal bovine serum, $100 \mathrm{U} \mathrm{mL}^{-1}$ penicillin 
and $100 \mathrm{mg} \mathrm{mL}^{-1}$ streptomycin. The cultures were maintained at $37^{\circ} \mathrm{C}$ under a humidified atmosphere and $5 \% \mathrm{CO}_{2}$. The cell lines were transferred every 3 or $4 \mathrm{~d}$. For experimental procedure, cells were seeded in 96-well plates at concentration of 10,000 cells per well in RPMI. After 24h incubation, the medium was removed, and $100 \mu \mathrm{L}$ fresh medium including the test sample was added to the cells. $100 \mu \mathrm{g} \mathrm{mL}^{-1}$ Doxorubicin, as a standard therapeutic drug was used as a positive control. Following compound addition, plates were cultured for $24 \mathrm{~h}$ at $37^{\circ} \mathrm{C}$. Afterwards, the assay was performed according to the manufacturer's instructions of CellTiterBlue Viability Assay and measured using the microplate reader Tecan Infinite M200 at excitation $560 \mathrm{~nm}$ and emission of $590 \mathrm{~nm}$. $\mathrm{IC}_{50}$ value was calculated as the concentration that shows $50 \%$ inhibition of the viability.

\section{Antibacterial assay}

Antimicrobial assay was performed using Xanthomonas campestris DSM 2405 . The cultivation took place in TSB medium (1.2\% tryptic soy broth; $0.5 \% \mathrm{NaCl}$ ). Overnight culture of the test organism was prepared and diluted to an optical density $(600 \mathrm{~nm})$ of 0.03 . To prepare the assay, the samples $\left(20 \mathrm{mg} \mathrm{mL}^{-1}\right.$ stock solution) were dissolved in medium and transferred into a 96-well microtiter plate and $200 \mu \mathrm{L}$ of the diluted culture was added to each well. The inoculated microplate was incubated for $7 \mathrm{~h}$ at $28^{\circ} \mathrm{C}$ and $200 \mathrm{rpm}$. To detect the inhibitory effect of the substances $10 \mu \mathrm{L}$ of a resazurin solution ( $0.3 \mathrm{mg} \mathrm{mL}^{-1}$ phosphate-buffered saline) was added to the microplate, incubated again for $1 \mathrm{~h}$ and the fluorescence signal $(560 \mathrm{~nm} / 590$ $\mathrm{nm}$ ) was measured using the microplate reader Tecan Infinite M200. Chloramphenicol was used as the positive control. $\mathrm{IC}_{50}$ value was calculated as the concentration that shows $50 \%$ inhibition of the viability.

\section{SUPPLEMENTARY INFORMATION}

Supplementary Information document (PDF) containing Supplementary Figures and Tables.

\section{DATA AVAILABILITY}

The genome sequence of D. muscorum LEGE 12446 is available at GenBank (Accession: JADEXS020000000). The GNPS dataset is available in MassIVE (MSV000088770). HRESIMS/MS spectra for 1-3 have been added to the GNPS Library under accessions CCMSLIB00009918389, CCMSLIB00009918390 and CCMSLIB00009918391, respectively. NMR data for 1-3 are available at DOI:10.6084/m9.figshare.19119107.

\section{AUTHOR INFORMATION}

\section{Corresponding Author}

*to whom correspondence should be addressed: Pedro N. Leão, pleao@ciimar.up.pt.

\section{Author Contributions}

SF and PNL designed research. SF carried out experimentation, with help from RCB. AW-S and DT contributed with the conceptualization and experimentation related to the evaluation of biological activity for the compounds. VMV contributed with indispensable materials. SF and PNL drafted the manuscript, with contributions from all co-authors.

\section{ACKNOWLEDGMENTS}

We thank support by Fundação para a Ciência e a Tecnologia (FCT) through grants UIDB/04423/2021 and UIDP/04423/2021 and scholarships SFRH/BD/116009/2016 to SF and $\mathrm{SFRH} / \mathrm{BD} / 136367 / 2018$ to $\mathrm{RCB}$. This project has received funding from the European Union's Horizon 2020 research and innovation programme under grant agreement No 952374.

\section{REFERENCES}

1 L. A. Gaysina, A. Saraf and P. Singh, in Cyanobacteria, Elsevier, 2019, pp. 1-28.

2 R. Haselkorn, Annu. Rev. Plant Physiol., 1978, 29, 319-344.

3 A. C. G. Chang, T. Chen, N. Li and J. Duan, Front. Microbiol., 2019, 10, 1888.

4 P. Lindblad, in Prokaryotic Symbionts in Plants, ed. K. Pawlowski, Springer Berlin Heidelberg, Berlin, Heidelberg, 2008, vol. 8, pp. 225233.

5 NCBI Genome, (accessed 29 January 2022).

6 R. V. Popin, D. O. Alvarenga, R. Castelo-Branco, D. P. Fewer and K. Sivonen, Front. Microbiol., 2021, 12, 684565.

7 P. M. Shih, D. Wu, A. Latifi, S. D. Axen, D. P. Fewer, E. Talla, A. Calteau, F. Cai, N. Tandeau de Marsac, R. Rippka, M. Herdman, K. Sivonen, T. Coursin, T. Laurent, L. Goodwin, M. Nolan, K. W. Davenport, C. S. Han, E. M. Rubin, J. A. Eisen, T. Woyke, M. Gugger and C. A. Kerfeld, Proc. Natl. Acad. Sci. U. S. A., 2013, 110, 1053-1058

8 B. S. Moore, J. L. Chen, G. M. L. Patterson, R. E. Moore, L. S. Brinen, Y. Kato and J. Clardy, J. Am. Chem. Soc., 1990, 112, 4061-4063.

9 R. M. Hohlman and D. H. Sherman, Nat. Prod. Rep., 2021, 38, 15671588 .

10 R. E. Schwartz, C. F. Hirsch, D. F. Sesin, J. E. Flor, M. Chartrain, R. E. Fromtling, G. H. Harris, M. J. Salvatore, J. M. Liesch and K. Yudin, J. Ind. Microbiol., 1990, 5, 113-123.

11 P. J. Proteau, W. H. Gerwick, F. Garcia-Pichel and R. Castenholz, Experientia, 1993, 49, 825-829.

12 U. Kaasalainen, D. P. Fewer, J. Jokela, M. Wahlsten, K. Sivonen and J. Rikkinen, Proc. Natl. Acad. Sci., 2012, 109, 5886-5891.

13 A. Liaimer, J. B. Jensen and E. Dittmann, Front. Microbiol., , DOI:10.3389/fmicb.2016.01693.

14 A. Liaimer, H. Jenke-Kodama, K. Ishida, K. Hinrichs, J. Stangeland, C. Hertweck and E. Dittmann, Environ. Microbiol. Rep., 2011, 3, 550558.

15 A. Liaimer, E. J. N. Helfrich, K. Hinrichs, A. Guljamow, K. Ishida, C. Hertweck and E. Dittmann, Proc. Natl. Acad. Sci., 2015, 112, 1862 1867.

16 D. P. Fewer, J. Jokela, L. Heinilä, R. Aesoy, K. Sivonen, T. Galica, P. Hrouzek and L. Herfindal, Physiol. Plant., 2021, 173, 639-650.

17 D. Kahne, C. Leimkuhler, W. Lu and C. Walsh, Chem. Rev., 2005, 105, $425-448$.

18 A. P. Tyurin, V. A. Alferova, A. S. Paramonov, M. V. Shuvalov, G. K. Kudryakova, E. A. Rogozhin, A. Y. Zherebker, V. A. Brylev, A. A. Chistov, A. A. Baranova, M. V. Biryukov, I. A. Ivanov, I. A. Prokhorenko, N. E. Grammatikova, T. V. Kravchenko, E. B. Isakova, E. P. Mirchink, E. G. Gladkikh, E. V. Svirshchevskaya, A. V. Mardanov, A. V. Beletsky, M. V. Kocharovskaya, V. V. Kulyaeva, A. S. Shashkov, D. E. Tsvetkov, N. E. Nifantiev, A. S. Apt, K. B. Majorov, S. S. Efimova, N. V. Ravin, E. N. Nikolaev, O. S. Ostroumova, G. S. Katrukha, O. A. Lapchinskaya, O. A. Dontsova, S. S. Terekhov, I. A. Osterman, Z. O. Shenkarev and V. A. Korshun, Angew. Chem. Int. Ed., 2021, 60, 18694-18703

19 T.-H. Bui, V. Wray, M. Nimtz, T. Fossen, M. Preisitsch, G. Schröder, K. Wende, S. E. Heiden and S. Mundt, J. Nat. Prod., 2014, 77, 1287 1296.

20 J. Vestola, T. K. Shishido, J. Jokela, D. P. Fewer, O. Aitio, P. Permi, M. Wahlsten, H. Wang, L. Rouhiainen and K. Sivonen, Proc. Natl. Acad. Sci., 2014, 111, E1909-E1917.

21 S. Somma, L. Gastaldo and A. Corti, Antimicrob. Agents Chemother., 1984, 26, 917-923. 
22 M. P. Singh, P. J. Petersen, W. J. Weiss, J. E. Janso, S. W. Luckman, E. B. Lenoy, P. A. Bradford, R. T. Testa and M. Greenstein, Antimicrob. Agents Chemother., 2003, 47, 62-69.

23 R. Ciabatti, J. K. Kettenring, G. Winters, G. Tuan, L. Zerilli and B. Cavalleri, J. Antibiot. (Tokyo), 1989, 42, 254-267.

24 S.-E. Lu, J. Novak, F. W. Austin, G. Gu, D. Ellis, M. Kirk, S. WilsonStanford, M. Tonelli and L. Smith, Biochemistry, 2009, 48, 8312-8321.

25 M. S. Butler, K. A. Hansford, M. A. T. Blaskovich, R. Halai and M. A. Cooper, J. Antibiot. (Tokyo), 2014, 67, 631-644.

26 V. Ramos, J. Morais, R. Castelo-Branco, Â. Pinheiro, J. Martins, A. Regueiras, A. L. Pereira, V. R. Lopes, B. Frazão, D. Gomes, C. Moreira, M. S. Costa, S. Brûle, S. Faustino, R. Martins, M. Saker, J. Osswald, P. N. Leão and V. M. Vasconcelos, J. Appl. Phycol., 2018, 30, 1437-1451.

27 M. Wang, J. J. Carver, V. V. Phelan, L. M. Sanchez, N. Garg, Y. Peng, D. D. Nguyen, J. Watrous, C. A. Kapono, T. Luzzatto-Knaan, C. Porto, A. Bouslimani, A. V. Melnik, M. J. Meehan, W.-T. Liu, M. Crüsemann, P. D. Boudreau, E. Esquenazi, M. Sandoval-Calderón, R. D. Kersten, L. A. Pace, R. A. Quinn, K. R. Duncan, C.-C. Hsu, D. J. Floros, R. G. Gavilan, K. Kleigrewe, T. Northen, R. J. Dutton, D. Parrot, E. E. Carlson, B. Aigle, C. F. Michelsen, L. Jelsbak, C. Sohlenkamp, P. Pevzner, A. Edlund, J. McLean, J. Piel, B. T. Murphy, L. Gerwick, C.-C. Liaw, Y.-L. Yang, H.-U. Humpf, M. Maansson, R. A. Keyzers, A. C. Sims, A. R. Johnson, A. M. Sidebottom, B. E. Sedio, A. Klitgaard, C. B. Larson, C. A. Boya P, D. Torres-Mendoza, D. J. Gonzalez, D. B. Silva, L. M. Marques, D. P. Demarque, E. Pociute, E. C. O’Neill, E. Briand, E. J. N. Helfrich, E. A. Granatosky, E. Glukhov, F. Ryffel, H. Houson, H. Mohimani, J. J. Kharbush, Y. Zeng, J. A. Vorholt, K. L. Kurita, P. Charusanti, K. L. McPhail, K. F. Nielsen, L. Vuong, M. Elfeki, M. F. Traxler, N. Engene, N. Koyama, O. B. Vining, R. Baric, R. R. Silva, S. J. Mascuch, S. Tomasi, S. Jenkins, V. Macherla, T. Hoffman, V. Agarwal, P. G. Williams, J. Dai, R. Neupane, J. Gurr, A. M. C. Rodríguez, A. Lamsa, C. Zhang, K. Dorrestein, B. M. Duggan, J. Almaliti, P.-M. Allard, P. Phapale, L.-F. Nothias, T. Alexandrov, M. Litaudon, J.-L. Wolfender, J. E. Kyle, T. O. Metz, T. Peryea, D.-T. Nguyen, D. VanLeer, P. Shinn, A. Jadhav, R. Müller, K. M. Waters, W. Shi, X. Liu, L. Zhang, R. Knight, P. R. Jensen, B. Ø. Palsson, K. Pogliano, R. G. Linington, M. Gutiérrez, N. P. Lopes, W. H. Gerwick, B. S. Moore, P. C. Dorrestein and N. Bandeira, Nat. Biotechnol., 2016, 34, 828-837.

28 H. Mohimani, A. Gurevich, A. Mikheenko, N. Garg, L.-F. Nothias, A Ninomiya, K. Takada, P. C. Dorrestein and P. A. Pevzner, Nat. Chem. Biol., 2017, 13, 30-37.

29 A. Gurevich, A. Mikheenko, A. Shlemov, A. Korobeynikov, H. Mohimani and P. A. Pevzner, Nat. Microbiol., 2018, 3, 319-327.

30 H. Mohimani, A. Gurevich, A. Shlemov, A. Mikheenko, A. Korobeynikov, L. Cao, E. Shcherbin, L.-F. Nothias, P. C. Dorrestein and P. A. Pevzner, Nat. Commun., 2018, 9, 4035.

31 Dictionary of Natural Products 32.0, https://dnp.chemnetbase.com, (accessed 20 December 2021).

32 J. A. van Santen, G. Jacob, A. L. Singh, V. Aniebok, M. J. Balunas, D. Bunsko, F. C. Neto, L. Castaño-Espriu, C. Chang, T. N. Clark, J. L.
Cleary Little, D. A. Delgadillo, P. C. Dorrestein, K. R. Duncan, J. M. Egan, M. M. Galey, F. P. J. Haeckl, A. Hua, A. H. Hughes, D. Iskakova, A. Khadilkar, J.-H. Lee, S. Lee, N. LeGrow, D. Y. Liu, J. M. Macho, C. S. McCaughey, M. H. Medema, R. P. Neupane, T. J. O’Donnell, J. S. Paula, L. M. Sanchez, A. F. Shaikh, S. Soldatou, B. R. Terlouw, T. A. Tran, M. Valentine, J. J. J. van der Hooft, D. A. Vo, M. Wang, D. Wilson, K. E. Zink and R. G. Linington, ACS Cent. Sci., 2019, 5, 1824 1833.

33 T. D. W. Claridge and I. Pérez-Victoria, Org Biomol Chem, 2003, 1, 3632-3634.

34 A. Usvalampi, Doctoral thesis, School of Chemical Technology, 2013.

35 Y. Zhang, S. Liu, H. Liu, X. Liu and Y. Che, J. Nat. Prod., 2009, 72, 1364-1367.

36 F. J. Ortiz-López, D. Carretero-Molina, M. Sánchez-Hidalgo, J. Martín, I. González, F. Román-Hurtado, M. Cruz, S. García-Fernández, F. Reyes, J. P. Deisinger, A. Müller, T. Schneider and O. Genilloud, Angew. Chem. Int. Ed., 2020, 59, 12654-12658.

37 K. Blin, S. Shaw, A. M. Kloosterman, Z. Charlop-Powers, G. P. van Wezel, M. H. Medema and T. Weber, Nucleic Acids Res., 2021, 49, W29-W35.

38 A. T. Keatinge-Clay, Chem. Biol., 2007, 14, 898-908.

39 M. A. Fischbach and C. T. Walsh, Chem. Rev., 2006, 106, 3468-3496.

40 N. A. Magarvey, B. Haltli, M. He, M. Greenstein and J. A. Hucul, Antimicrob. Agents Chemother., 2006, 50, 2167-2177.

41 L. Favrot, J. S. Blanchard and O. Vergnolle, Biochemistry, 2016, 55, 989-1002.

42 D. M. Daigle, D. W. Hughes and G. D. Wright, Chem. Biol., 1999, 6, 99-110.

43 S. S. Hegde, F. Javid-Majd and J. S. Blanchard, J. Biol. Chem., 2001, 276, 45876-45881.

44 I. W. Hamley, Chem. Commun., 2015, 51, 8574-8583.

45 M. M. Gehringer, L. Adler, A. A. Roberts, M. C. Moffitt, T. K. Mihali, T. J. T. Mills, C. Fieker and B. A. Neilan, ISME J., 2012, 6, 1834-1847.

46 D. Dehm, J. Krumbholz, M. Baunach, V. Wiebach, K. Hinrichs, A Guljamow, T. Tabuchi, H. Jenke-Kodama, R. D. Süssmuth and E. Dittmann, ACS Chem. Biol., , DOI:10.1021/acschembio.9b00240.

47 K. Gutiérrez-García, E. D. Bustos-Díaz, J. A. Corona-Gómez, H. E. Ramos-Aboites, N. Sélem-Mojica, P. Cruz-Morales, M. A. Pérez-Farrera, F. Barona-Gómez and A. Cibrián-Jaramillo, Genome Biol. Evol., 2019, 11, 319-334.

48 S. Honda, E. Akao, S. Suzuki, M. Okuda, K. Kakehi and J. Nakamura, Anal. Biochem., 1989, 180, 351-357.

49 D. E. Wood and S. L. Salzberg, Genome Biol., 2014, 15, R46.

50 A. Bankevich, S. Nurk, D. Antipov, A. A. Gurevich, M. Dvorkin, A. S. Kulikov, V. M. Lesin, S. I. Nikolenko, S. Pham, A. D. Prjibelski, A. V. Pyshkin, A. V. Sirotkin, N. Vyahhi, G. Tesler, M. A. Alekseyev and P. A. Pevzner, J. Comput. Biol., 2012, 19, 455-477.

51 Y.-W. Wu, B. A. Simmons and S. W. Singer, Bioinformatics, 2016, 32, 605-607. 